\title{
A spectrophotometric comparison of the physical properties of classical Cepheids and nonvariable supergiants and bright giants
}

\author{
R. S. Patterson
}

J.S. Neff

Follow this and additional works at: https://bearworks.missouristate.edu/articles-cnas

\section{Recommended Citation}

Patterson, Robert S., and John S. Neff. "A spectrophotometric comparison of the physical properties of classical Cepheids and nonvariable supergiants and bright giants." The Astrophysical Journal Supplement Series 41 (1979): 215-241.

This article or document was made available through BearWorks, the institutional repository of Missouri State University. The work contained in it may be protected by copyright and require permission of the copyright holder for reuse or redistribution.

For more information, please contact BearWorks@library.missouristate.edu. 
The Astrophysical Journal Supplement Series, 41:215-241, 1979 October

(C) 1979. The American Astronomical Society. All rights reserved. Printed in U.S.A.

\title{
A SPECTROPHOTOMETRIC COMPARISON OF THE PHYSICAL PROPERTIES OF CLASSICAL CEPHEIDS AND NONVARIABLE SUPERGIANTS AND BRIGHT GIANTS
}

\author{
Robert S. Patterson and John S. NefF \\ Department of Physics and Astronomy, University of Iowa \\ Received 1978 July 31; accepted 1979 March 14
}

\begin{abstract}
Spectrophotometric observations using $30 \AA$ resolution in the wavelength range $3408-5910 \AA$ have been obtained for nine classical Cepheids with $\log P$ (days) from 0.29 to 1.43 over several phases and for $14 \mathrm{~F}, \mathrm{G}$, and $\mathrm{K}$ spectral-type supergiants and bright giants. The observations were obtained in order to make an empirical comparison of the physical properties of the Cepheids and the nonvariables which have similar spectral types. Flux distributions for all stars were normalized to $4700 \AA$ and corrected for interstellar reddening. The observed flux distributions are tabulated for all observations. The nonvariable stars were compared to existing models, and significant deviations between observations and models were found for wavelengths between 3408 and $4600 \AA$ over a wide temperature range. Strengths of strongest absorption features were determined from the intrinsic flux distributions, but no significant differences were found between the two types of stars. Ratios of intrinsic flux distributions show that $\alpha$ Per matched $\delta$ Cep and $\eta$ Aql near maximum within the errors of measurement. At other phases of these two Cepheids their continua can generally be matched by that of a nonvariable star to within \pm 0.1 spectral types. However, real differences remain at most observed phases which do not appear to be due entirely to luminosity differences. Similar results were found for DT Cyg, T Vul, and X Cyg.
\end{abstract}

Subject headings: spectrophotometry - stars: Cepheids - stars: supergiants

\section{INTRODUCTION}

The existence of both stable and variable stars on the H-R diagram in what is called the Cepheid instability strip has been demonstrated by several investigators. Schmidt (1972a) showed that four of 11 $\mathrm{F}$ and $\mathrm{G}$ spectral type supergiants, whose temperatures were measured by means of $\mathrm{H} \alpha$ line profiles and whose absolute magnitudes were gathered from the literature, fell more than 2 standard error limits within the instability strip. Fernie and Hube (1971) examined 48 stars with MK spectral types similar to those of the classical Cepheids. They found that 43 of the 48 were stable to within $0.01 \mathrm{mag}$. They then showed that several of these stars fell within conservative boundaries for the Cepheid instability strip. One of the stars Fernie and Hube suspected of variability $(\epsilon$ Leo, 0.09 mag) was assumed to be a nonvariable in the present study.

Cox, King, and Tabor (1973) reported theoretical results which can explain this overlap in terms of the mass fraction of helium in a given star. According to their results, stars with helium mass fraction between 0.28 and 0.38 would pulsate, but not those with less than 0.20. Schmidt, Rosendhal, and Jewsbury (1974) found no significant difference in element abundance of three Cepheids and 11 normal supergiants, but they did find a lower surface gravity for the Cepheids, which they interpreted as being consistent with the helium abundance requirement suggested by Cox et al.

Until now, observations of Cepheids have consisted with a few exceptions of either high-resolution photo- graphic spectrograms or low-resolution wide-band filter photometry. A new body of data has been assembled here consisting of medium-resolution narrow-band photoelectric spectrophotometry of selected classical Cepheids and nonvariable supergiants and bright giants. An empirical comparison is made of the observed spectrophotometric properties of these two types of stars in hope of further understanding the overlap of variables and nonvariables in the Cepheid instability strip.

\section{OBSERVATIONS}

The observations were made with the University of Iowa Observatory $61 \mathrm{~cm}$ telescope and photoelectric spectrophotometer described by Neff and Clements (1972, 1973). The instrumental profile was triangular with a full width at half-maximum response of $30.1 \AA$, and measurements were made at $30.1 \AA$ intervals in the wavelength region $3408-5910 \AA$. One or two standard stars were measured nightly over a wide range in air mass in order to compute atmospheric extinction, and the flux standards $\alpha$ Lyr and/or $\alpha$ Leo were scanned each night to determine instrumental sensitivity.

Combination of uncertainties in determination of extinction coefficients, instrumental sensitivity, and detector output current amounts to typical errors in the relative flux distributions of $21 \%$ at the wavelength extremes and $2 \%$ near $4700 \AA$.

Program star characteristics are listed in Tables 1 and 2 for the Cepheids and nonvariables, respectively. The HR numbers are those from the Catalogue of 
TABLE 1

Absolute Magnitudes and MK Spectral Types at Maximum and Minimum for Nine Classical Cepheids

\begin{tabular}{|c|c|c|c|c|c|c|c|}
\hline \multirow[b]{2}{*}{ HR } & \multirow[b]{2}{*}{ NAME } & \multirow{2}{*}{$\begin{array}{c}\text { PERIOD } \\
\text { (days) }\end{array}$} & \multicolumn{2}{|c|}{$M_{V}$} & \multirow[b]{2}{*}{ AUTHORITIES* } & \multicolumn{2}{|c|}{ SPectral TyPe } \\
\hline & & & $\operatorname{Max}$ & Min & & $\operatorname{Max}$ & Min \\
\hline 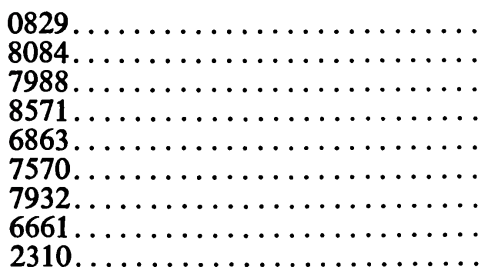 & $\begin{array}{l}\text { SU Cas } \\
\text { DT Cyg } \\
\text { T Vul } \\
\delta \text { Cep } \\
\text { Y Sgr } \\
\eta \text { Aql } \\
\text { X Cyg } \\
\text { Y Oph } \\
\text { T Mon }\end{array}$ & $\begin{array}{r}1.95 \\
2.50 \\
4.44 \\
5.37 \\
5.77 \\
7.18 \\
16.39 \\
17.12 \\
27.02\end{array}$ & $\begin{array}{l}-2.53 \\
-2.86 \\
-3.66 \\
-3.94 \\
-4.01 \\
-4.31 \\
-5.28 \\
-5.19 \\
-5.95\end{array}$ & $\begin{array}{l}-2.18 \\
-2.56 \\
-3.02 \\
-3.13 \\
-3.28 \\
-3.50 \\
-4.29 \\
-4.70 \\
-4.96\end{array}$ & $\begin{array}{l}1,2,3,4 \\
1,2,3,4 \\
1,2,4 \\
1,2,3,4 \\
1,2,3,4 \\
1,2,3,4 \\
1,2,3,4 \\
1,2,4 \\
1,3,4\end{array}$ & $\begin{array}{l}\text { F5 Ib-II } \\
\text { F5.5 I-II } \\
\text { F5 Ib } \\
\text { F5 Ib } \\
\text { F6 } \\
\text { F6.5 Ib } \\
\text { F7 Ib } \\
\text { F8 Ib } \\
\text { F7 Iab }\end{array}$ & $\begin{array}{l}\text { F7 Ib } \\
\text { F7 I-II } \\
\text { G0 Ib } \\
\text { G2 Ib } \\
\text { G5 } \\
\text { G2 Ib } \\
\text { G8 Ib } \\
\text { G3 Ib } \\
\text { K1 Iab }\end{array}$ \\
\hline
\end{tabular}

* Authorities for $M_{V}$ : (1) Parsons and Bouw 1971. (2) Wielen 1974. (3) Fernie and Hube 1968. (4) Kraft 1961.

Bright Stars (Hoffleit 1964), while the periods and spectral types of the Cepheids are from Kukarkin et al. (1969). The spectral type for the nonvariables is in each case the consensus of the determinations listed in the Navy $U B V$ catalog (Blanco et al. 1968).

The observed normalized flux distributions are presented for the nonvariables and the Cepheids in Appendices $\mathbf{A}$ and $\mathbf{B}$, respectively. In each case $\lambda$ represents the central wavelength in angstroms of channel $N, F_{\lambda} / F_{\lambda 0}$ is the flux at each wavelength normalized to the value at $4700 \AA$, and $\sigma$ is the standard deviation of the normalized flux in each channel. For each observation the logarithm of the absolute flux at $4700 \AA$, in watts per square meter per angstrom, determined from the relative spectrophotometry and the absolute flux of $\alpha$ Lyr given by Neff et al. (1976) is listed at the foot of each column. The Cepheid flux distributions are listed in order of increasing period and phase in the light curve.

\section{DETERMINATION OF INTRINSIC FLUX DISTRIBUTIONS}

The observed flux distributions were corrected for interstellar reddening according to the law determined

TABLE 2

Absolute Magnitudes and MK SPectral Types for 14 NONVARIABLES

\begin{tabular}{|c|c|c|c|c|}
\hline HR & Name & $M_{V}$ & Authorities* & $\begin{array}{c}\text { Spectral } \\
\text { Type }\end{array}$ \\
\hline $\begin{array}{l}2693 \ldots \ldots \\
1865 \ldots \ldots \\
1017 \ldots \ldots \\
7796 \ldots \ldots \\
8232 \ldots \ldots \\
1603 \ldots \ldots \\
8414 \ldots \ldots \\
8313 \ldots \ldots \\
2473 \ldots \ldots \\
8465 \ldots \ldots \\
3873 \ldots \ldots \\
6536 \ldots \ldots \\
2630 \ldots \ldots \\
4392 \ldots \ldots \\
\end{array}$ & $\begin{array}{l}\delta \mathrm{CMa} \\
\alpha \mathrm{Lep} \\
\alpha \mathrm{Per} \\
\gamma \mathrm{Cyg} \\
\beta \mathrm{Aqr} \\
\beta \mathrm{Cam} \\
\alpha \mathrm{Aqr} \\
9 \mathrm{Peg} \\
\epsilon \mathrm{Gem} \\
\zeta \mathrm{Cep} \\
\epsilon \mathrm{Leo} \\
\beta \mathrm{Dra} \\
\omega \mathrm{Gem} \\
56 \mathrm{UMa}\end{array}$ & $\begin{array}{l}-7.1 \\
-4.5 \\
-4.6 \\
-4.5 \\
-4.9 \\
-5.2 \\
-5.2 \\
-4.7 \\
-4.8 \\
-4.5 \\
-2.1 \\
-6.4 \\
-3.2 \\
-0.2\end{array}$ & $\begin{array}{l}3,5,6 \\
8 \\
3,4,6 \\
8 \\
1,2,3,7 \\
1,2,3 \\
1,2,3,7 \\
7 \\
1,2,7 \\
1,2,7 \\
1,7 \\
1,7 \\
1,2 \\
1\end{array}$ & $\begin{array}{l}\text { F8 Ia } \\
\text { F0 Ib } \\
\text { F5 Ib } \\
\text { F8 Ib } \\
\text { G0 Ib } \\
\text { G0 Ib } \\
\text { G2 Ib } \\
\text { G5 Ib } \\
\text { G8 Ib } \\
\text { K1 Ib } \\
\text { G0 II } \\
\text { G2 II } \\
\text { G5 II } \\
\text { G8 II }\end{array}$ \\
\hline
\end{tabular}

* Authorities for $M_{V}$ : (1) Wilson and Bappu 1957. (2) Kraft et al. 1964. (3) Parsons and Bouw 1971. (4) Schmidt-Kaler 1961. (5) Feinstein 1967. (6) Osmer 1972. (7) Schmidt 1972a. (8) Keenan 1963. by Underhill and Walker (1966) by using color excesses tabulated from the literature. The recent reddening law by Schild (1977) emphasizes that the linear relation used by Underhill and Walker is an approximation. However, a comparison of the two laws shows no disagreement larger than the errors of measurement in this work. For the Cepheids the adopted values of color excess are just the means of the values from the nine sources listed in Table 3 . The typical standard deviation of the mean for these values is about $0.06 \mathrm{mag}$. An uncertainty in Cepheid color excess of $0.06 \mathrm{mag}$ would produce a corresponding uncertainty in the ability to match flux distributions of about 0.1 spectral types. Results obtained for Cepheids based on methods using supergiants have been included since the mean values calculated excluding supergiant methods differ from those adopted here by at most $0.05 \mathrm{mag}$ in the case of T Mon. The color excesses for the nonvariables were calculated from $B-V$ measurements compiled in the Navy catalog (Blanco et al. 1968) and from intrinsic color indexes, $(B-V)_{0}$, averaged over the intrinsic color functions from the sources cited in Table 4 .

The intrinsic flux distributions are presented for the nonvariables in Figures 1 and 2, and for the Cepheids near maximum and minimum brightness in Figures 3 and 4 , respectively.

\section{COMPARISON}

An attempt was made to calibrate the effective temperatures and gravities of the nonvariables in terms of existing model atmospheres. The intrinsic normalized flux distributions were compared to some of the models of Parsons (1969) and Johnson (1974). There were major deviations between the models and observations in the wavelength region 3408-4600 $\AA$ even though reasonable temperature matches were achieved. The deviations precluded suitable calibration of the nonvariables.

The strengths of the strongest absorption features in the spectra of the nonvariables and Cepheids were also compared. Unfortunately for this traditional method of analyzing spectra, the differences due to luminosity were about the same size as the errors in measuring the line strengths. No convincing evidence was found for 


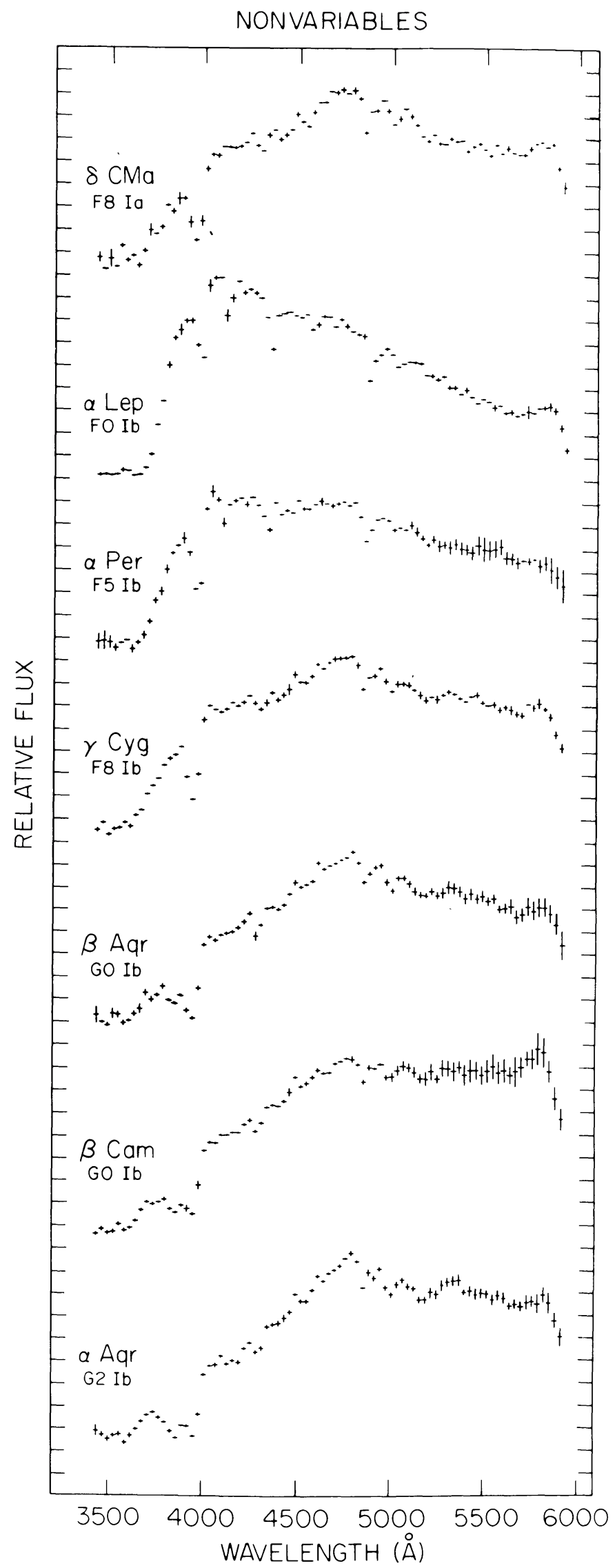

FIG. 1.- Intrinsic flux distributions for nonvariables normalized to value at $4700 \AA$. Relative flux is indicated by horizontal lines. Vertical lines represent \pm 1 standard deviation from the mean. 


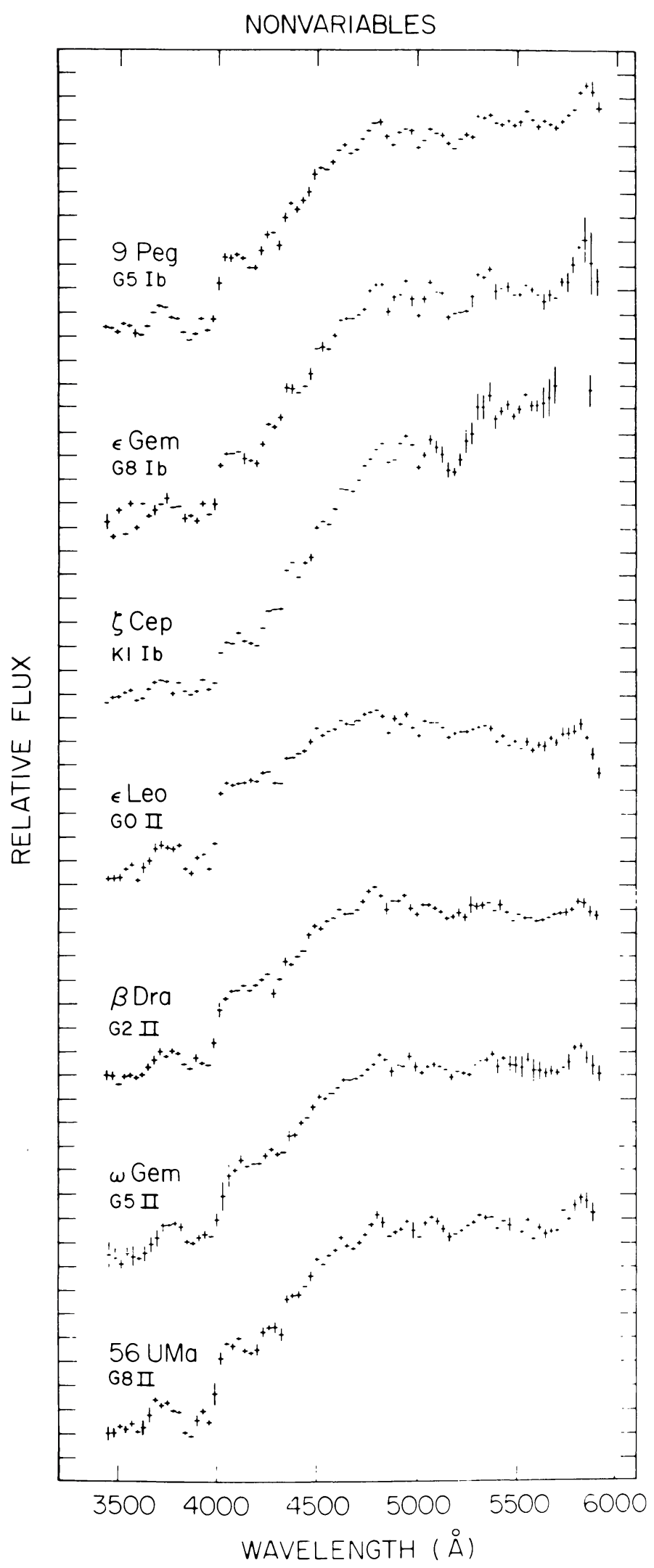

Fig. 2.- Intrinsic flux distributions for nonvariables normalized to value at $4700 \AA$. Relative flux is indicated by horizontal lines. Vertical lines represent \pm 1 standard deviation from the mean. 


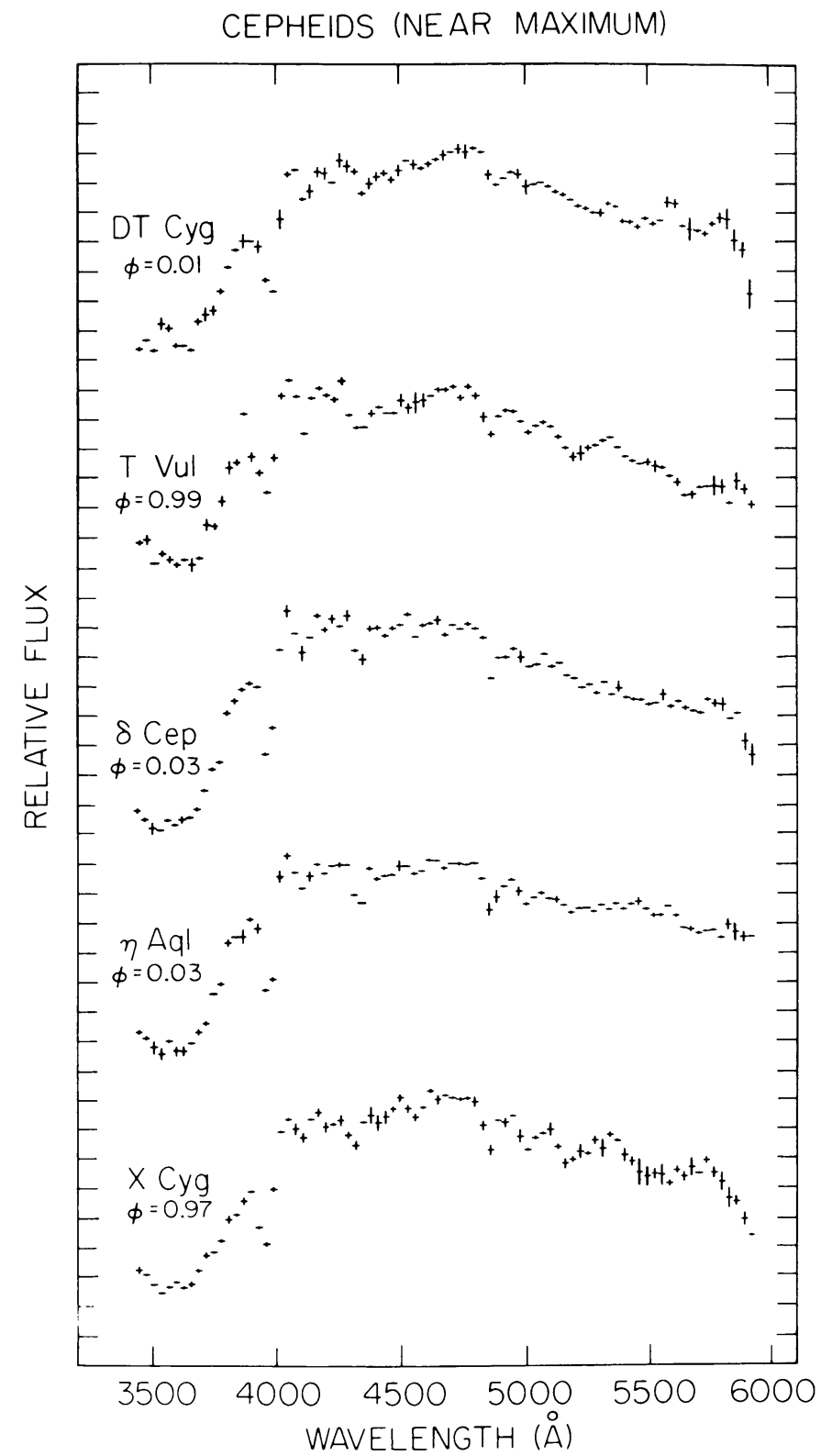

FIG. 3.-Intrinsic flux distributions for five Cepheids near maximum normalized to the value at $4700 \AA$. Symbols same as in Fig. 1, except $\phi$ denotes the phase in the light cycle.

TABLE 3

COLOR EXCESSES OF CEPHEIDS

(in hundredths of a magnitude)

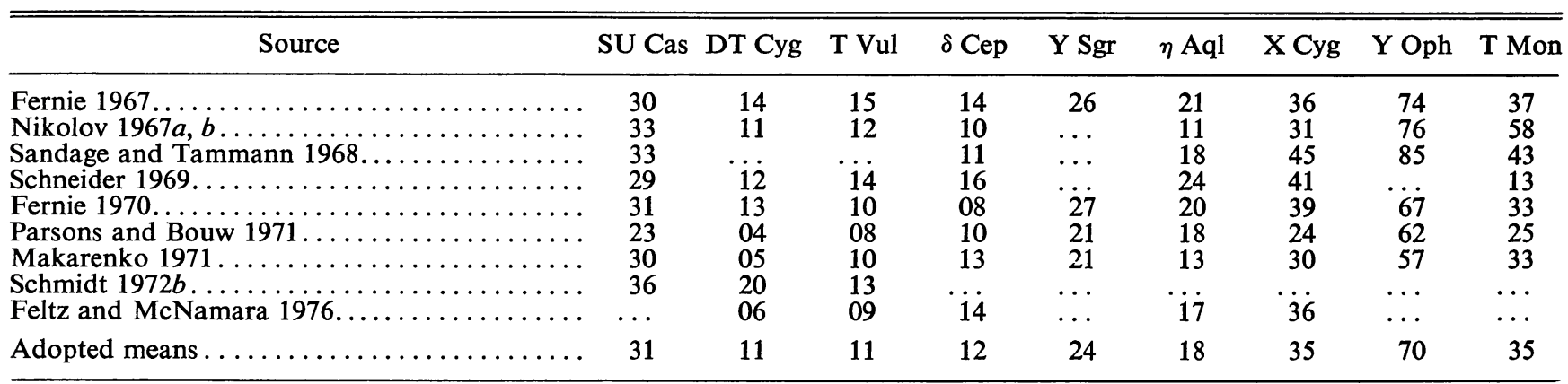




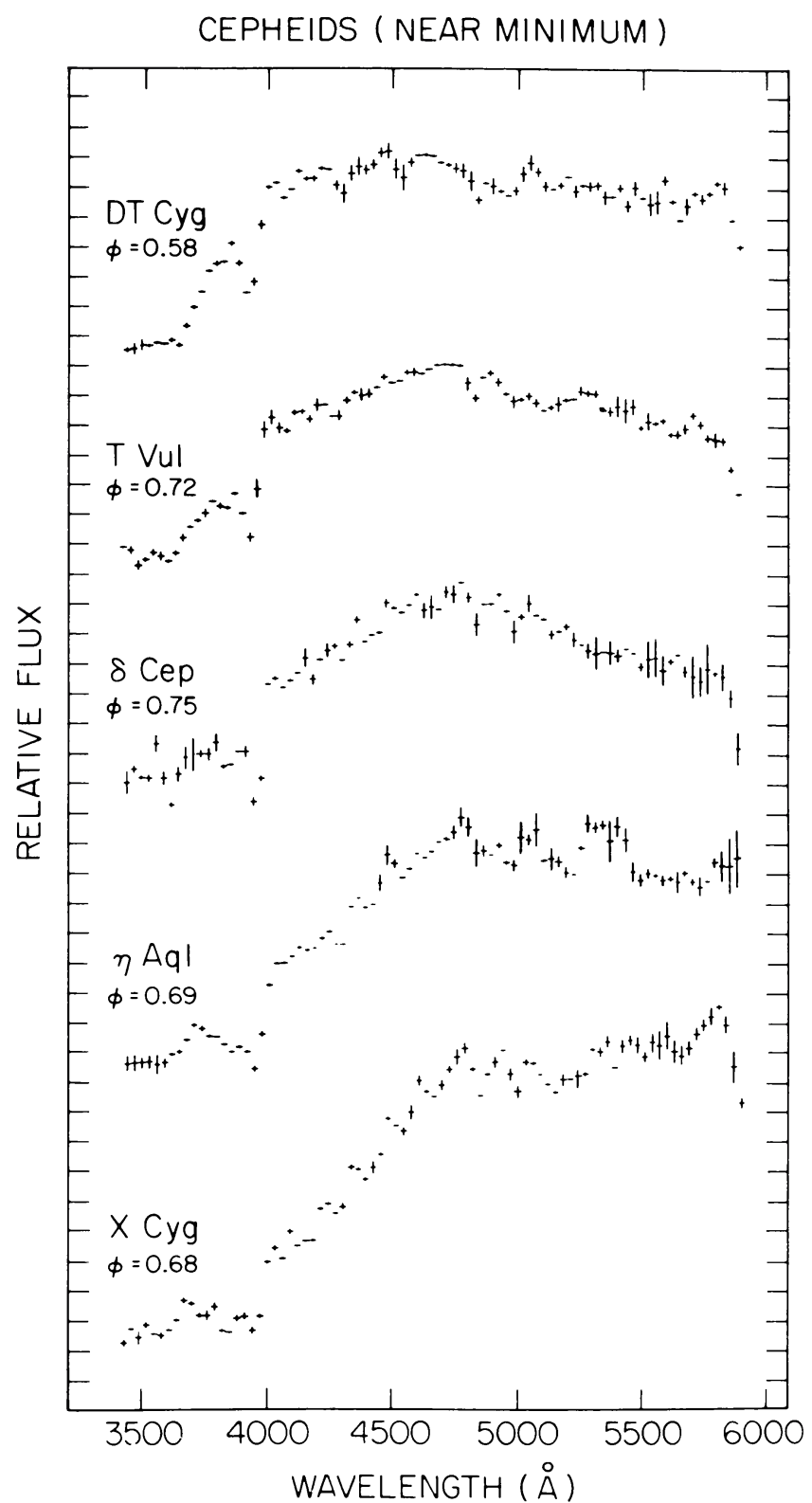

Fig. 4.-Intrinsic flux distributions for five Cepheids near minimum normalized to the value at $4700 \AA$. Symbols same as in Fig. 1, except $\phi$ denotes the phase in the light cycle.

any differences between Cepheids and nonvariables using this method.

The continuous flux distributions of the Cepheids were systematically compared to those of the nonvariables. A nonvariable that would best match each observed phase of the five Cepheids DT Cyg, T Vul, $\delta$ Cep, $\eta$ Aql, and X Cyg was selected by a combination of $\chi^{2}$ minimization and visual inspection of ratio spectra of Cepheids divided by nonvariables. In order to interpret the ratio spectra for the Cepheids, ratio spectra between pairs of nonvariables were computed for various temperature and luminosity differences. The results of the division of a G2 Ib flux distribution into the flux distributions of three hotter and three cooler luminosity class Ib stars are given in Figures 5 and 6 , respectively. The characteristics of ratio spectra indicating a progressively hotter numerator star as shown in Figure 5 are as follows: increasing negative slope of the spectrum, increasing relative excess at $3850 \AA$, and an increase in relative strength of the $\mathrm{H} \gamma$ and $\mathrm{H} \delta$ lines with increasing temperature differences. Figure 6 shows a trend to increasing positive slope for ratio spectra of progressively cooler numerator stars.

Differences in ratio spectra due to luminosity are shown in Figure 7, where flux ratios of luminosity class II to Ib for four nonvariables of $\mathrm{G}$ spectral type are given. Relative differences for $\epsilon$ Leo $/ \beta$ Aqr and $\beta$ Dra $/ \alpha$ Aqr are small, but there is a relative excess of 
TABLE 4

Color EXCESSES OF NoNVARIABles (in hundredths of a magnitude)

\begin{tabular}{|c|c|c|c|c|}
\hline Star & $B-$ & $V(B-V)_{0}$ & Authorities* & $E_{B-V}$ \\
\hline 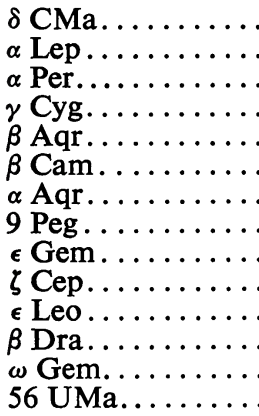 & 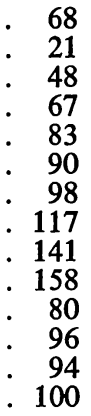 & $\begin{array}{r}59 \\
17 \\
37 \\
59 \\
75 \\
75 \\
86 \\
99 \\
109 \\
124 \\
71 \\
82 \\
87 \\
97\end{array}$ & $\begin{array}{l}1,2,3,4,5 \\
1,2,3,4,5 \\
1,2,3,4,5 \\
1,2,3,4,5 \\
1,2,3,4,5 \\
1,2,3,4,5 \\
1,2,3,4,5 \\
1,2,3,5 \\
1,2,3,5 \\
1,2,3,5 \\
3,5 \\
3,5 \\
3,5 \\
3,5\end{array}$ & $\begin{array}{l}09 \\
04 \\
11 \\
08 \\
08 \\
15 \\
12 \\
18 \\
32 \\
34 \\
09 \\
14 \\
07 \\
03\end{array}$ \\
\hline
\end{tabular}

*Authorities for intrinsic color functions: (1) Feinstein 1959. (2) Kraft and Hiltner 1961. (3) FitzGerald 1970. (4) Parsons 1971. (5) Kron 1978.

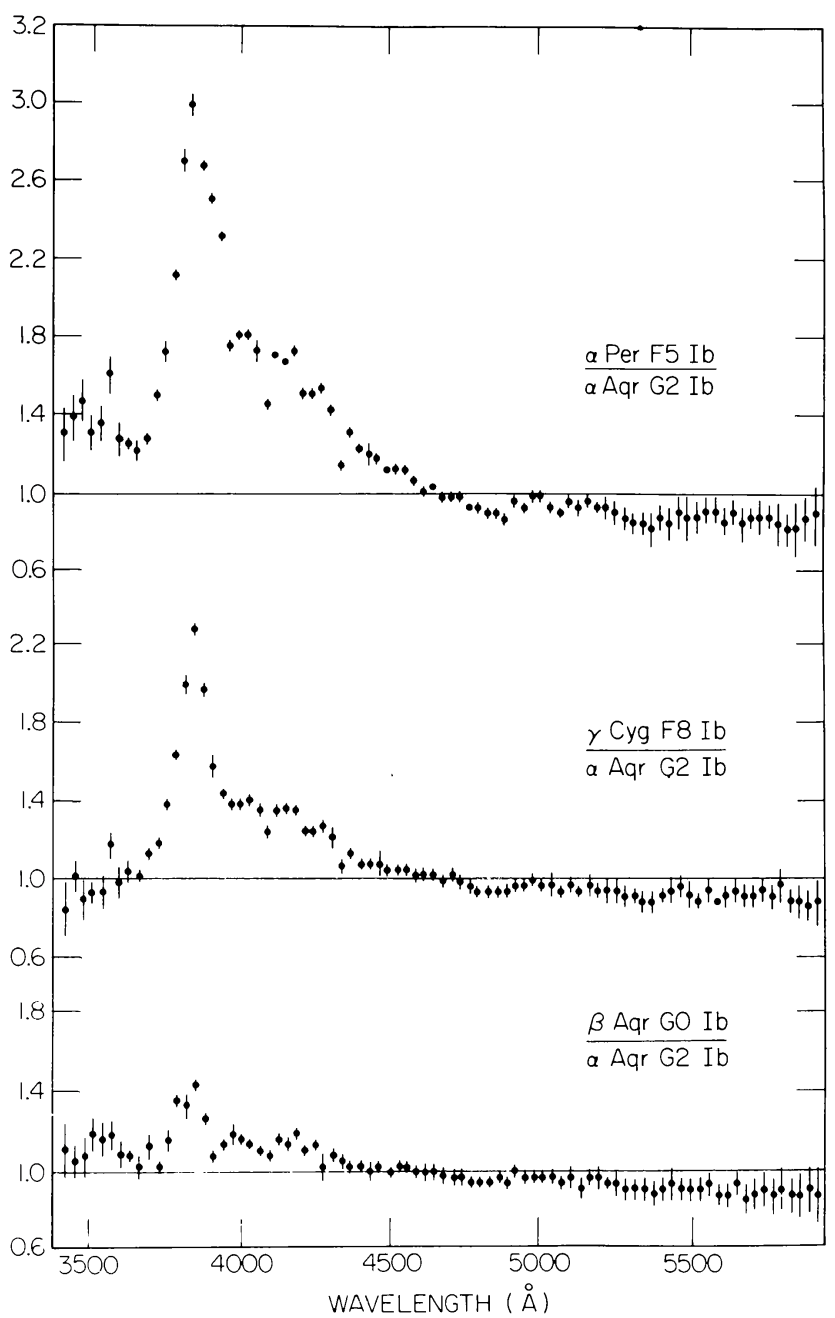

Fig. 5.-Ratio spectra for three supergiants hotter than $\alpha$ Aqr. Circles indicate flux ratios which are normalized to $4700 \AA$. Vertical lines represent \pm 1 standard deviation from the mean.

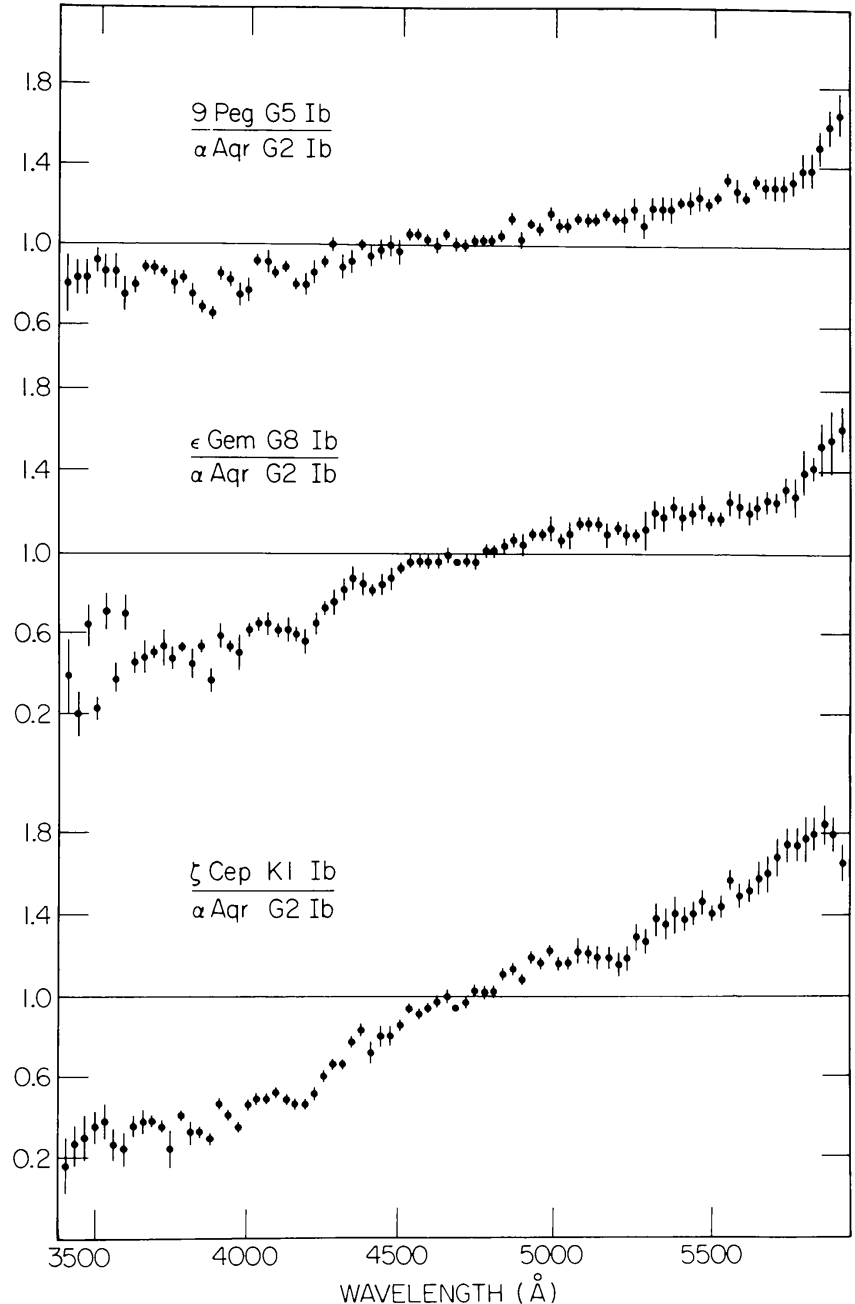

Fig. 6.--Ratio spectra for three supergiants cooler than $\alpha$ Aqr. Symbols same as in Fig. 5.

flux around $3500-4300 \AA$ for $\omega \mathrm{Gem} / 9 \mathrm{Peg}$ and $56 \mathrm{UMa} / \zeta$ Cep.

The ratio spectra of the Cepheids to nonvariables were inspected using Figures 5, 6, and 7 as guidelines. The results of this comparison are illustrated in Figures 8 and 9, which show the ratio spectra for 10 observed phases of $\delta$ Cep. The best fits to the nonvariable stars are seen to be appropriate temperature choices by generally flat ratio spectra. It is not clear if the remaining differences are due to luminosity since the effect is small near the effective temperature of $\delta$ Cep, as is seen for the G0 II/G0 Ib ratio in Figure 7. Notable differences in relative absorption-line strengths can be seen at phases 0.50 and 0.60 where the $\mathrm{Ca}$ II $\mathrm{H}$ and $\mathrm{K}$ lines are 3 standard deviations stronger and phases 0.90 and 0.94 where they become 3 or 4 standard deviations weaker than in the nonvariables.

Since the continua of $\delta \mathrm{Cep}, \eta \mathrm{Aql}$, and X Cyg were matched well by luminosity class II nonvariables at some phases near minimum, the absolute magnitudes of both Cepheids and nonvariables have been gathered from the literature and plotted in Figure 10 for 


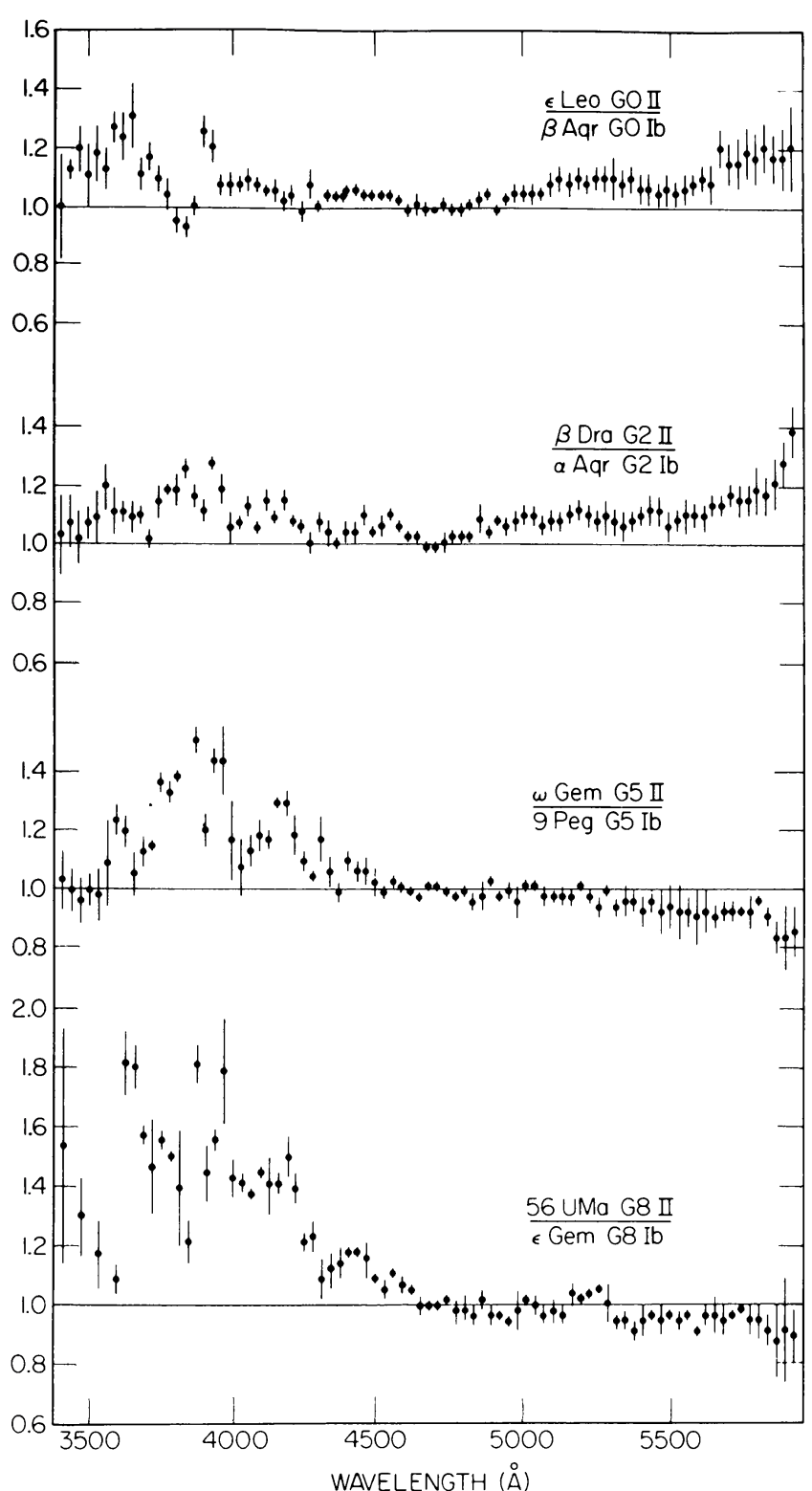

Fig. 7.-Ratio spectra of luminosity class II to Ib for four MK spectral types. Symbols same as in Fig. 5.

comparison. The absolute magnitudes and sources are listed in Tables 1 and 2. The $M_{V}$ for the Cepheids at maximum and minimum were determined from light curves of Mitchell et al. (1964).

The adopted absolute magnitudes are plotted in Figure 10 as a function of $G_{B}$, the gradient of the intrinsic flux distribution in the blue region from 4400 to $4800 \AA$. This parameter was found to be a linear function of the intrinsic color index of the nonvariables listed in Table 4. The Cepheids DT Cyg, T Vul, $\delta$ Cep, and $\eta$ Aql have absolute magnitudes near minimum which are significantly below those of luminosity class Ib supergiants. Conservative error bars are shown for $\alpha$ Lep in Figure 10. The star $\beta$ Dra is suspect because of conflicting spectral type and $M_{V}$ determinations.

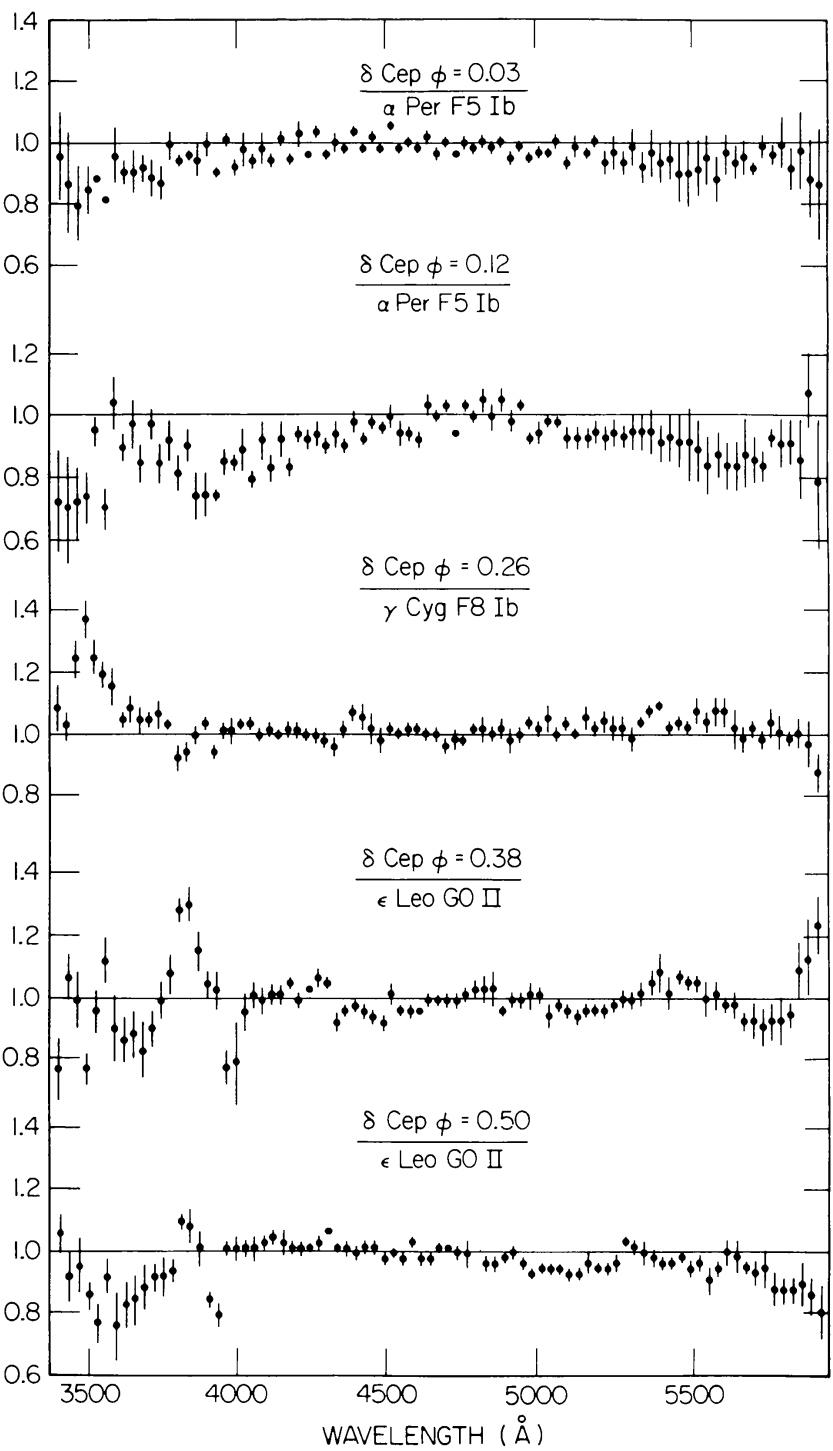

FIg. 8.-Ratio spectra of $\delta$ Cep with respect to nonvariables for phases $\varphi=0.03-0.50$. Symbols same as in Fig. 5 .

\section{DISCUSSION}

By comparing intrinsic flux distributions, a nonvariable with the same effective temperature could be found for most phases of the Cepheids to about \pm 0.2 spectral types. Near maximum, $\delta$ Cep and $\eta$ Aql were matched by $\alpha$ Per within the errors of measurement. It should be noted that even though the effective temperatures are similar for two stars because their continua match, this does not guarantee that they have the same $T-\tau$ relation.

At phases other than maximum, real differences in the ratio spectra of these two Cepheids to nonvariables were found. It is not clear whether the deviations were the same as effects due to luminosity difference noted in the pairs of nonvariables (Fig. 7).

Real differences in the ratio spectra of $\delta$ Cep were found at certain phases. For example, there is an excess in flux relative to $\gamma$ Cyg for wavelengths less 


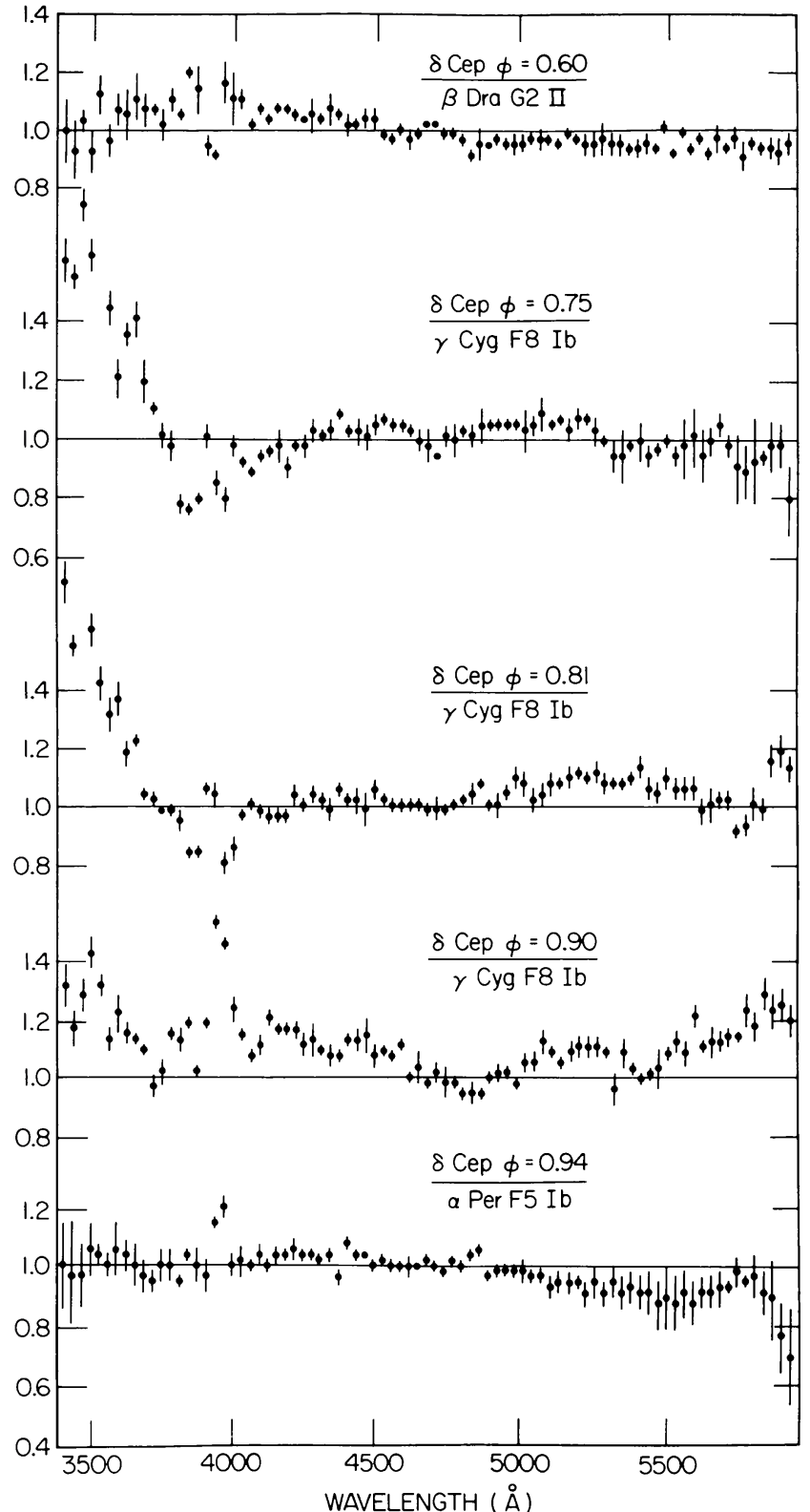

FIG. 9.-Ratio spectra of $\delta$ Cep with respect to nonvariables for phases $\phi=0.60-0.94$. Symbols same as in Fig. 5 .

than $3650 \AA$ at phase 0.26 shown in Figure 8. The rest of the spectrum is flat, indicating a good temperature match. The simplest explanation of this phenomenon is that the size of the Balmer discontinuity is different for the two stars at that phase of $\delta$ Cep. Since the Balmer discontinuity is gravity sensitive, it was hypothesized that changes in pulsational acceleration could

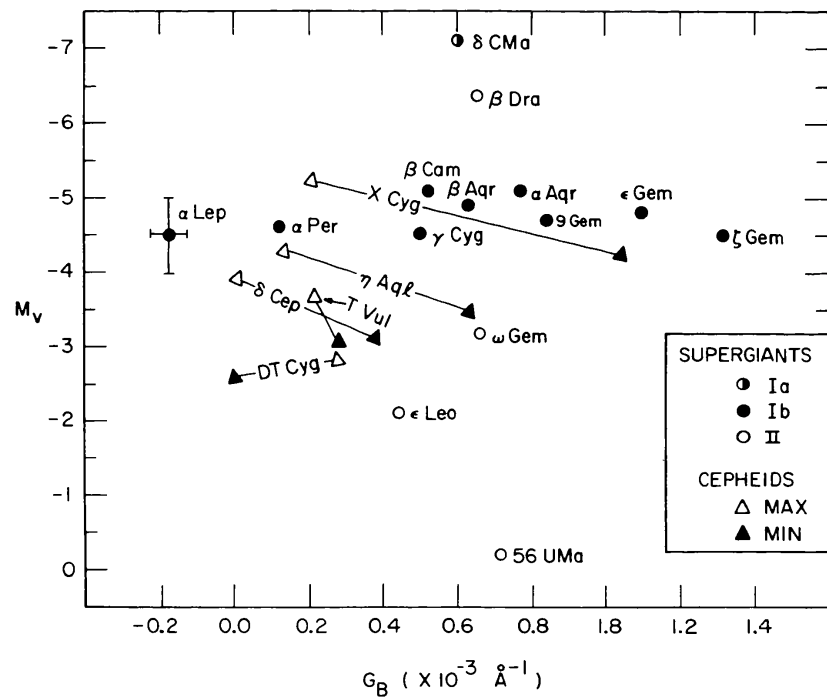

FIG. 10.-Absolute magnitudes of nonvariables and Cepheids versus the gradient of the intrinsic flux distribution $G_{B}$ in the region $4400-4800 \AA$. Luminosity classes and Cepheid maxima and minima are indicated.

be responsible for differences in the ratio spectra for wavelengths less than $3650 \AA$. According to the radial velocity measurements of Shane (1958), the acceleration due to pulsation in $\delta$ Cep between phases 0.15 and 0.85 remains approximately constant. However, inspection of the ratio spectra for phase 0.26 in Figure 8 and phase 0.75 in Figure 9 shows that the relative flux for wavelengths less than $3650 \AA$ increased by a factor of 2 during this phase interval relative to the same nonvariable. Pulsational acceleration is therefore not responsible for this change in ratio spectra. It is probably due to an increase in pressure in the atmosphere of $\delta \mathrm{Cep}$, which is consistent with the inward acceleration of the star's atmosphere during this phase interval.

Any differences in the chemical composition of the two types of stars as suggested by Cox, King, and Tabor (1973) are probably masked by differences in the temperature and pressure structure of the atmospheres of the Cepheids and nonvariables. Until the atmospheric structures of these high-luminosity stars are better understood, our data cannot be used to determine chemical composition differences between Cepheids and nonvariables.

We thank Dr. G. E. Kron for providing some of his results before publication. We are grateful to M. Claussen, G. Clements, D. Dee, K. Gillies, D. Ketelsen, D. Ringgenberg, L. Schroeder, and V. Smith for assistance in obtaining and reducing the data.

\section{APPENDIX A}

Table 5 lists the name of the star, the Bright Star Catalog number, and the MK spectral type for each nonvariable. $N$ is the channel number whose central wavelength is $\lambda$. For each channel the observed normalized flux $F_{\lambda} / \lambda_{\lambda_{0}}$ and its standard deviation $\sigma$ are given. The flux is normalized to the value at $4700 \AA$, and both $F_{\lambda} / F_{\lambda_{0}}$ and $\sigma$ have been multiplied by 1000 . After the last entry for each star the log of the absolute flux in watts per square meter per angstrom at $4700 \AA$ is given. 
TABLE 5

Observed Normalized Flux Distributions for the Nonvariables

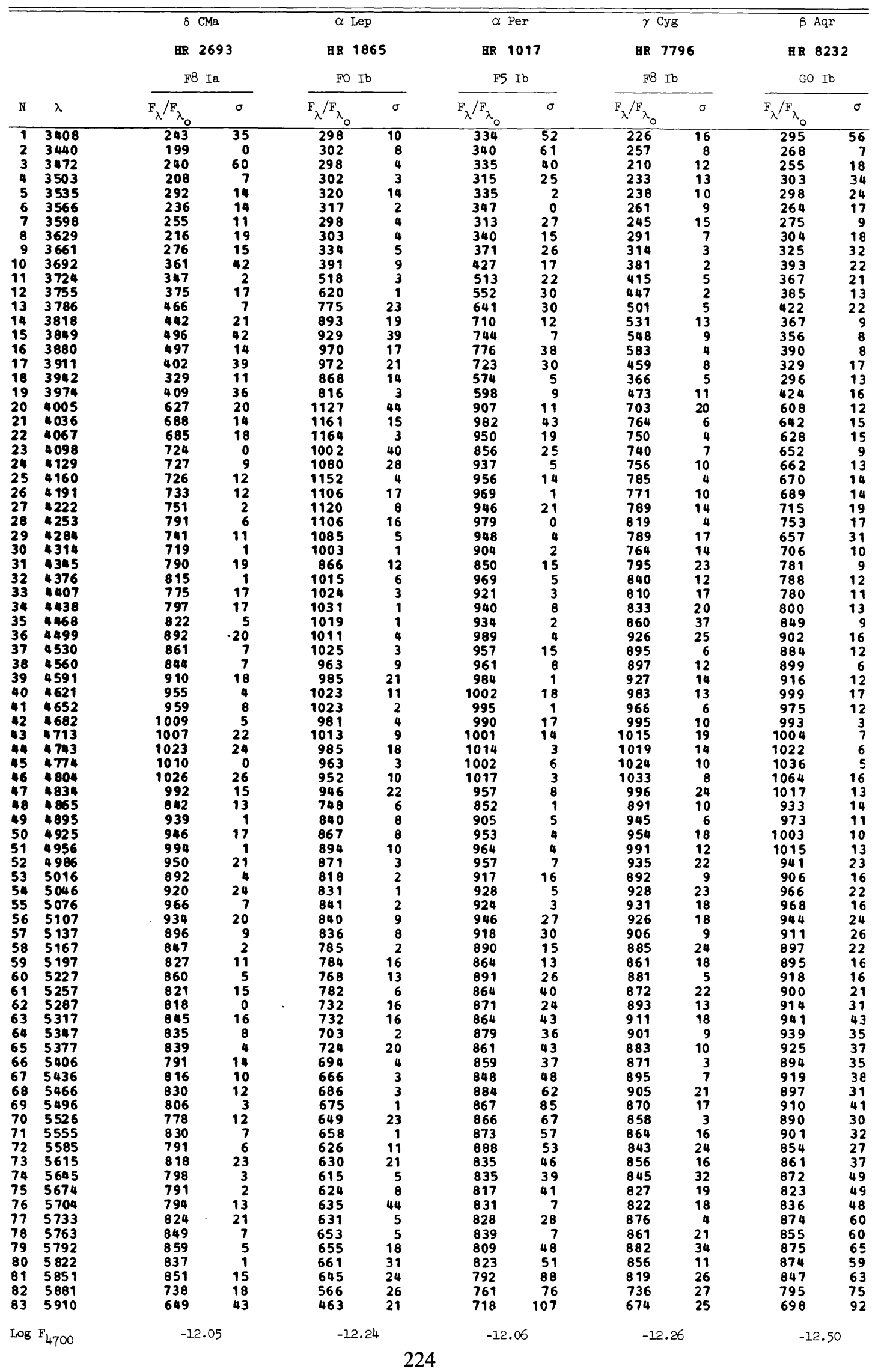


TABLE 5-Continued

\begin{tabular}{|c|c|c|c|c|c|c|c|c|c|c|c|}
\hline & & $\beta C$ & & $\alpha \mathrm{A}$ & & $9 \mathrm{P}$ & & $\in G$ & & $6 \mathrm{Ce}$ & \\
\hline & & HR 1 & & AR 8 & & HR & & HR 2 & & HR 8 & \\
\hline & & GO & & G2 & & G5 & & G8 & & $\mathrm{KI}$ & \\
\hline $\mathrm{N}$ & $\lambda$ & ${ }^{F}{ }_{\lambda} / F_{\lambda_{0}}$ & $\sigma$ & $\mathrm{F}_{\lambda} / \mathrm{F}_{\lambda_{0}}$ & $\sigma$ & $F_{\lambda} / F_{\lambda_{0}}$ & $\sigma$ & ${ }^{F} \lambda^{/ F} \lambda_{0}$ & $\sigma$ & ${ }^{F}{ }_{\lambda} / F_{\lambda_{0}}$ & $\sigma$ \\
\hline $\begin{array}{l}1 \\
2\end{array}$ & $\begin{array}{l}3408 \\
3440\end{array}$ & 217 & 12 & 252 & 37 & 190 & 13 & 90 & 48 & 43 & 2 \\
\hline $\begin{array}{l}2 \\
3\end{array}$ & $\begin{array}{l}3440 \\
3472\end{array}$ & 237 & 15 & 239 & 21 & 188 & 5 & 49 & 18 & 59 & 19 \\
\hline 3 & $\begin{array}{l}3472 \\
3503\end{array}$ & 224 & 14 & 224 & 22 & 175 & 15 & 124 & 22 & 61 & 16 \\
\hline $\begin{array}{l}4 \\
5\end{array}$ & $\begin{array}{r}3503 \\
3535\end{array}$ & 229 & 15 & 239 & 15 & 205 & 11 & 56 & 1 & 74 & 11 \\
\hline $\begin{array}{l}5 \\
6\end{array}$ & $\begin{array}{r}3535 \\
3566\end{array}$ & $\begin{array}{r}258 \\
237\end{array}$ & & $\begin{array}{l}243 \\
213\end{array}$ & 21 & 199 & $\begin{array}{l}11 \\
27\end{array}$ & $\begin{array}{r}147 \\
77\end{array}$ & 22 & 82 & 13 \\
\hline 7 & $\begin{array}{l}3566 \\
3598\end{array}$ & 248 & $\begin{array}{r}14 \\
9\end{array}$ & $\begin{array}{l}213 \\
241\end{array}$ & $\begin{array}{l}15 \\
20\end{array}$ & $\begin{array}{l}174 \\
170\end{array}$ & $\begin{array}{r}27 \\
6\end{array}$ & $\begin{array}{r}77 \\
150\end{array}$ & $\begin{array}{r}18 \\
5\end{array}$ & $\begin{array}{l}53 \\
60\end{array}$ & ${ }_{8}^{8}$ \\
\hline 8 & 3629 & 276 & 9 & 267 & 10 & 202 & 5 & 114 & 14 & 88 & g \\
\hline${ }_{10}^{9}$ & 3661 & 318 & 10 & 299 & 11 & 251 & 3 & 133 & 34 & 109 & 13 \\
\hline 10 & 3692 & 351 & 9 & 326 & 8 & 278 & 9 & 154 & 5 & 118 & 1 \\
\hline $\begin{array}{l}19 \\
12\end{array}$ & 3724 & 346 & 11 & 338 & 9 & 274 & 2 & 173 & 36 & 115 & 8 \\
\hline $\begin{array}{l}12 \\
13\end{array}$ & 3755 & 354 & 5 & 318 & 13 & 240 & 10 & 147 & 4 & 79 & 19 \\
\hline $\begin{array}{l}13 \\
14\end{array}$ & 3786 & 367 & 13 & 302 & 6 & 237 & 8 & 151 & 2 & 114 & 4 \\
\hline $\begin{array}{l}14 \\
15\end{array}$ & 3818 & 331 & 10 & 266 & 14 & 190 & 3 & 114 & 28 & 88 & 4 \\
\hline $\begin{array}{l}15 \\
16\end{array}$ & 3849 & 318 & 7 & 240 & 7 & 162 & 1 & 123 & 11 & 78 & 4 \\
\hline 96 & 3880 & 348 & 9 & 293 & 8 & 186 & 8 & 108 & 21 & 90 & 11 \\
\hline 17 & & 336 & 22 & 291 & 9 & 242 & 11 & 166 & 20 & 129 & 4 \\
\hline 18 & 3942 & 317 & 9 & 250 & 6 & 201 & 7 & 131 & 4 & 98 & 10 \\
\hline 19 & 3974 & 433 & 29 & 341 & 11 & 244 & 24 & 168 & 39 & 120 & 2 \\
\hline 20 & 4005 & 574 & 6 & 504 & 8 & 378 & 43 & 302 & 19 & 224 & 3 \\
\hline 21 & $\begin{array}{l}4036 \\
4067\end{array}$ & 609 & 8 & 541 & 6 & 478 & 27 & 344 & 11 & 261 & 8 \\
\hline 22 & $\begin{array}{l}4067 \\
4098\end{array}$ & 609 & 7 & 547 & 17 & 477 & 26 & 348 & 4 & 259 & 4 \\
\hline 23 & $\begin{array}{l}4098 \\
4\end{array}$ & 644 & 5 & 586 & 8 & 492 & 14 & 357 & 3 & 299 & \\
\hline 24 & 4129 & 648 & 2 & 556 & 13 & 481 & 12 & 336 & 37 & 273 & 8 \\
\hline 25 & 4160 & 661 & 3 & 571 & 11 & 448 & 7 & 331 & 10 & 267 & 12 \\
\hline 26 & 4191 & 663 & 1 & 566 & 16 & 450 & 19 & 324 & 24 & 262 & 2 \\
\hline 27 & 4222 & 699 & 9 & 625 & 11 & 517 & 30 & 396 & 21 & 327 & $\overline{1}$ \\
\hline 28 & 4253 & 720 & 14 & 651 & 7 & 581 & 25 & 472 & 11 & 391 & 0 \\
\hline 29 & 4284 & 675 & 11 & 614 & 16 & 592 & 6 & 466 & 15 & 400 & 2 \\
\hline 30 & 4314 & 712 & 11 & 632 & 18 & 544 & 32 & 504 & 24 & 405 & 10 \\
\hline 31 & 4345 & 782 & 5 & 728 & 15 & 657 & 30 & 618 & 32 & 552 & 5 \\
\hline 32 & 4376 & 795 & 8 & 738 & 15 & 717 & 13 & 620 & 33 & 586 & 1 \\
\hline 33 & 4407 & 793 & 4 & 746 & 21 & 695 & 22 & 610 & 2 & 535 & 5 \\
\hline 34 & 4438 & 817 & 10 & 770 & 26 & 735 & 23 & 639 & 3 & 595 & 12 \\
\hline 35 & 4468 & 861 & 25 & 799 & 18 & 774 & 32 & 695 & 40 & 623 & 26 \\
\hline 36 & 4499 & 929 & 9 & 879 & 8 & 849 & 36 & 802 & 3 & 747 & 16 \\
\hline 37 & 4530 & 894 & 11 & 853 & 16 & 881 & 7 & 817 & 33 & 781 & 3 \\
\hline 38 & 4560 & 912 & 18 & 856 & 16 & 879 & 3 & 817 & 7 & 777 & 3 \\
\hline 39 & 4591 & 943 & 17 & 908 & 13 & 915 & 19 & 880 & 16 & 850 & 6 \\
\hline 40 & 4621 & 979 & 9 & 971 & 14 & 970 & 5 & 952 & 6 & 942 & 1 \\
\hline 41 & 4652 & 971 & 8 & 954 & 9 & 999 & 18 & 969 & 11 & 949 & 2 \\
\hline 42 & 4682 & 977 & 8 & 992 & 9 & 969 & 4 & 978 & 2 & 952 & 3 \\
\hline 43 & 4713 & 1022 & 8 & 1010 & 10 & 989 & 8 & 1003 & 7 & 1008 & 1 \\
\hline 44 & 4743 & 1038 & 5 & 1032 & 15 & 1040 & 6 & 1035 & 13 & 1080 & 6 \\
\hline 45 & 4774 & 1057 & 7 & 1069 & 5 & 1082 & 7 & 1126 & 37 & 1119 & 9 \\
\hline 46 & 4804 & 1056 & 22 & 1097 & 15 & 1119 & 5 & 1161 & 35 & 1172 & 2 \\
\hline 47 & 4834 & 1038 & 10 & 1063 & 10 & 1130 & 24 & 1173 & 20 & 1210 & 5 \\
\hline 48 & 4865 & 963 & 20 & 949 & 7 & 1074 & 21 & 1064 & 34 & 1139 & 4 \\
\hline 49 & 4895. & 1033 & 18 & 1020 & 15 & 1044 & 9 & 1140 & 33 & 1160 & 1 \\
\hline 50 & 4925 & 1033 & 9 & 999 & 18 & 1103 & 8 & 1159 & 10 & 1245 & 5 \\
\hline 51 & 4956 & 1057 & 8 & 1044 & 17 & 1124 & 2 & 1232 & 13 & 1291 & 13 \\
\hline 52 & 4986 & 1002 & 20 & 963 & 18 & 1122 & 29 & 1161 & 51 & 1262 & 9 \\
\hline 53 & 5016 & 1009 & 31 & 935 & 15 & 1052 & 10 & 1094 & 17 & 1168 & 13 \\
\hline 54 & 5046 & 1042 & 33 & 983 & 24 & 1088 & 2 & 1181 & 31 & 1237 & 20 \\
\hline 55 & 5076 & 1067 & 34 & 1007 & 18 & 1146 & 9 & 1266 & 32 & 1320 & 36 \\
\hline 56 & 5107 & 1064 & 29 & 980 & 22 & 1130 & 3 & 1233 & 2 & 1297 & 42 \\
\hline 57 & 5137 & 1045 & 34 & 973 & 18 & 1128 & 22 & 1238 & 25 & 1274 & 58 \\
\hline 58 & 5167 & 1021 & 33 & 925 & 24 & 1096 & 15 & 1131 & 29 & 1207 & 48 \\
\hline 59 & 5197 & 1022 & 43 & 928 & 24 & 1077 & 3 & 1159 & 5 & 1209 & 30 \\
\hline 60 & 5227 & 1063 & 54 & 967 & 32 & 1127 & 4 & 1174 & 5 & 1280 & 40 \\
\hline 61 & 5257 & 1032 & 29 & 959 & 27 & 1150 & 20 & 1188 & 10 & 1384 & $7 C$ \\
\hline 62 & 5287 & 1085 & 57 & 1003 & 35 & 1145 & 15 & 1270 & 72 & 1431 & 68 \\
\hline 63 & 5317 & 1088 & 50 & 1020 & 31 & 1246 & 22 & 1389 & 28 & 1578 & 87 \\
\hline 64 & 5347 & 1078 & 63 & 1029 & 33 & 1243 & 15 & 1385 & 33 & 1589 & 77 \\
\hline 65 & 5377 & 1100 & 45 & 1034 & 37 & 1261 & 16 & 1436 & 31 & 1661 & 86 \\
\hline 66 & 5406 & 1068 & 69 & 980 & 20 & 1232 & 7 & $\begin{array}{l}1334 \\
1358\end{array}$ & 54 & $\begin{array}{r}1553 \\
1506\end{array}$ & 64 \\
\hline 67 & 5436 & 1093 & 77 & 990 & 35 & 1229 & 18 & 1358 & 4 & 1606 & 29 \\
\hline 68 & 5466 & 1099 & 61 & 976 & 36 & 1253 & 24 & 1376 & 40 & 1652 & 33 \\
\hline 69 & 5496 & 1078 & 63 & 986 & 30 & 1237 & 16 & 1344 & 6 & 1604 & 24 \\
\hline 70 & 5526 & 1102 & 77 & 984 & 25 & 1258 & 30 & 1355 & 19 & 1653 & 29 \\
\hline 71 & 5555 & 1129 & 86 & 958 & 30 & 1313 & 10 & 1413 & 5 & 1742 & 12 \\
\hline 72 & 5585 & 1102 & 74 & 979 & 30 & 1277 & 8 & 1399 & 17 & 1697 & 34 \\
\hline 73 & 5615 & 1115 & 79 & 968 & 34 & 1251 & 23 & 1381 & 2 & 1712 & 39 \\
\hline 74 & 5645 & 1096 & 57 & 933 & 20 & 1280 & 13 & 1354 & 54 & 1735 & 101 \\
\hline 75 & 5674 & 1120 & 100 & 946 & 32 & 1270 & 11 & 1399 & 38 & 1778 & 120 \\
\hline 76 & 5704 & 1144 & 71 & 935 & 33 & 1259 & 19 & 1392 & 6 & 1856 & 114 \\
\hline 77 & 5733 & 1190 & 51 & 957 & 47 & 1293 & 17 & 1489 & 29 & 1990 & 95 \\
\hline 78 & 5763 & 1193 & 68 & 965 & 38 & 1329 & 12 & 1497 & 63 & 1998 & 138 \\
\hline 79 & 5792 & 1248 & 108 & 955 & 66 & 1361 & 7 & 1603 & 56 & 2021 & 119 \\
\hline 80 & 5822 & 1235 & 97 & 1000 & 52 & 1449 & 15 & 1711 & 14 & 2156 & 101 \\
\hline 81 & 5851 & 1140 & 72 & 964 & 70 & 1490 & 36 & 1761 & 146 & 2138 & 73 \\
\hline 82 & 5881 & 1005 & 78 & 877 & 53 & 1464 & 74 & 1642 & 202 & 1903 & 106 \\
\hline 83 & 5910 & 901 & 72 & 798 & 60 & 1386 & 68 & 1549 & 89 & 1607 & 23 \\
\hline Log & $F_{4700}$ & -13 & & -12 & & -13 & & -12 & & & \\
\hline
\end{tabular}


TABLE 5-Continued

\begin{tabular}{|c|c|c|c|c|c|c|c|c|c|}
\hline \multirow[b]{2}{*}{$\mathrm{N}$} & \multirow[b]{2}{*}{$\lambda$} & \multicolumn{2}{|c|}{$\begin{array}{c}\epsilon \text { Leo } \\
\text { HB } \mathbf{3 8 7 3} \\
\text { GO II }\end{array}$} & \multicolumn{2}{|c|}{$\begin{array}{c}\text { B Dra } \\
\text { AB } 6536 \\
\text { G2 II }\end{array}$} & \multicolumn{2}{|c|}{$\begin{array}{l}\omega \text { Gem } \\
\text { BR } 2630 \\
\text { G5 II }\end{array}$} & \multicolumn{2}{|c|}{$\begin{array}{c}56 \text { UMa } \\
\text { HR } 4392 \\
\text { G8 II }\end{array}$} \\
\hline & & ${ }^{F} \lambda / F_{\lambda_{0}}$ & $\sigma$ & ${ }^{F} \lambda^{/ F} \gamma_{0}$ & $\sigma$ & $\mathrm{F}_{\lambda} / \mathrm{F}_{\lambda_{0}}$ & $\sigma$ & $F_{\lambda} / F_{\lambda_{0}}$ & $\sigma$ \\
\hline $\begin{array}{l}1 \\
2 \\
3 \\
44 \\
5 \\
6 \\
7 \\
8 \\
99 \\
10 \\
11 \\
12 \\
13 \\
14 \\
15 \\
16 \\
17 \\
18 \\
19 \\
20 \\
21 \\
22 \\
23 \\
24 \\
25 \\
26 \\
27 \\
28 \\
29 \\
30 \\
31 \\
32 \\
33 \\
34 \\
35 \\
36 \\
37 \\
38 \\
39 \\
40 \\
41 \\
42 \\
43 \\
44 \\
45 \\
46 \\
47 \\
48 \\
49 \\
50 \\
51 \\
52 \\
53 \\
54 \\
55 \\
56 \\
57 \\
58 \\
59 \\
60 \\
61 \\
62 \\
63 \\
64 \\
65 \\
66 \\
67 \\
68 \\
69 \\
70 \\
71 \\
72 \\
73 \\
74 \\
75 \\
76 \\
77 \\
78 \\
79 \\
80 \\
81 \\
82 \\
83\end{array}$ & 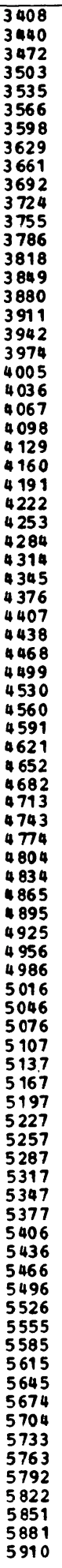 & 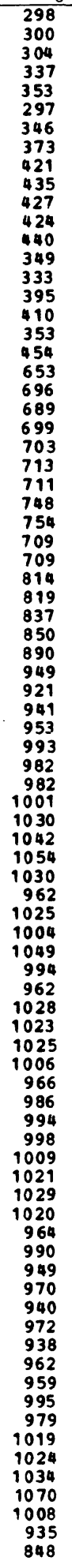 & $\begin{array}{r}21 \\
24 \\
27 \\
13 \\
23 \\
15 \\
38 \\
28 \\
35 \\
33 \\
20 \\
23 \\
16 \\
12 \\
20 \\
18 \\
7 \\
11 \\
9 \\
17 \\
15 \\
15 \\
12 \\
12 \\
23 \\
10 \\
11 \\
4 \\
9 \\
1 \\
10 \\
0 \\
5 \\
14 \\
17 \\
10 \\
14 \\
11 \\
11 \\
1 \\
14 \\
4 \\
4 \\
15 \\
10 \\
33 \\
13 \\
11 \\
22 \\
10 \\
17 \\
11 \\
18 \\
11 \\
3 \\
1 \\
6 \\
14 \\
18 \\
8 \\
16 \\
13 \\
13 \\
6 \\
25 \\
15 \\
7 \\
12 \\
27 \\
17 \\
18 \\
35 \\
15 \\
27 \\
48 \\
44 \\
46 \\
35 \\
11 \\
38 \\
41\end{array}$ & $\begin{array}{l}252 \\
251 \\
223 \\
251 \\
257 \\
249 \\
249 \\
260 \\
290 \\
317 \\
351 \\
335 \\
355 \\
348 \\
310 \\
295 \\
337 \\
317 \\
311 \\
397 \\
526 \\
570 \\
602 \\
607 \\
628 \\
611 \\
634 \\
658 \\
683 \\
608 \\
666 \\
740 \\
732 \\
732 \\
766 \\
791 \\
860 \\
900 \\
894 \\
929 \\
946 \\
987 \\
972 \\
977 \\
998 \\
1037 \\
1085 \\
1108 \\
1074 \\
1020 \\
1061 \\
1065 \\
1093 \\
1040 \\
1019 \\
1064 \\
1067 \\
1057 \\
1044 \\
1018 \\
1030 \\
1051 \\
1035 \\
1093 \\
1091 \\
1099 \\
1114 \\
1082 \\
1111 \\
1080 \\
1046 \\
1077 \\
1064 \\
1068 \\
1056 \\
1064 \\
1079 \\
1096 \\
1106 \\
1112 \\
1129 \\
1170 \\
1167 \\
1126 \\
1112\end{array}$ & $\begin{array}{r}31 \\
27 \\
4 \\
17 \\
17 \\
15 \\
15 \\
24 \\
30 \\
24 \\
9 \\
20 \\
11 \\
4 \\
5 \\
27 \\
11 \\
1 \\
33 \\
48 \\
14 \\
10 \\
3 \\
6 \\
6 \\
8 \\
12 \\
44 \\
30 \\
7 \\
31 \\
11 \\
5 \\
0 \\
27 \\
19 \\
16 \\
10 \\
11 \\
7 \\
11 \\
0 \\
4 \\
16 \\
20 \\
10 \\
15 \\
45 \\
11 \\
11 \\
15 \\
33 \\
22 \\
13 \\
14 \\
16 \\
16 \\
22 \\
13 \\
27 \\
24 \\
53 \\
23 \\
24 \\
2 \\
2 \\
38 \\
12 \\
1 \\
5 \\
14 \\
1 \\
10 \\
16 \\
6 \\
9 \\
11 \\
14 \\
21 \\
32 \\
42 \\
32\end{array}$ & $\begin{array}{c}225 \\
214 \\
192 \\
234 \\
220 \\
215 \\
235 \\
270 \\
296 \\
347 \\
348 \\
336 \\
346 \\
342 \\
285 \\
279 \\
302 \\
315 \\
309 \\
375 \\
470 \\
553 \\
576 \\
617 \\
594 \\
606 \\
608 \\
640 \\
667 \\
649 \\
658 \\
726 \\
731 \\
783 \\
806 \\
851 \\
895 \\
891 \\
891 \\
914 \\
941 \\
976 \\
979 \\
986 \\
1001 \\
1028 \\
1051 \\
1094 \\
1077 \\
1029 \\
1058 \\
1054 \\
1099 \\
1056 \\
1032 \\
1060 \\
1072 \\
1066 \\
1054 \\
1023 \\
1048 \\
1044 \\
1039 \\
1082 \\
1102 \\
1108 \\
1135 \\
1083 \\
1120 \\
1095 \\
1094 \\
1087 \\
1122 \\
1078 \\
1077 \\
1068 \\
1079 \\
1073 \\
1097 \\
1122 \\
1189 \\
1197 \\
1145 \\
1113 \\
1078 \\
\end{array}$ & $\begin{array}{r}80 \\
63 \\
29 \\
37 \\
69 \\
11 \\
51 \\
52 \\
57 \\
47 \\
10 \\
20 \\
29 \\
18 \\
14 \\
25 \\
28 \\
4 \\
44 \\
94 \\
73 \\
19 \\
39 \\
6 \\
1 \\
6 \\
25 \\
17 \\
19 \\
0 \\
39 \\
21 \\
20 \\
3 \\
28 \\
31 \\
12 \\
0 \\
5 \\
16 \\
2 \\
7 \\
7 \\
13 \\
13 \\
16 \\
19 \\
39 \\
2 \\
7 \\
31 \\
30 \\
24 \\
4 \\
17 \\
8 \\
4 \\
21 \\
33 \\
16 \\
17 \\
23 \\
40 \\
68 \\
58\end{array}$ & $\begin{array}{c}189 \\
191 \\
217 \\
206 \\
229 \\
198 \\
215 \\
266 \\
328 \\
306 \\
318 \\
285 \\
280 \\
196 \\
183 \\
247 \\
286 \\
240 \\
358 \\
502 \\
564 \\
553 \\
586 \\
537 \\
527 \\
541 \\
614 \\
632 \\
633 \\
604 \\
752 \\
767 \\
772 \\
808 \\
853 \\
923 \\
902 \\
940 \\
963 \\
1018 \\
984 \\
973 \\
999 \\
1033 \\
1075 \\
1118 \\
1087 \\
1030 \\
1047 \\
1061 \\
1095 \\
1058 \\
1031 \\
1090 \\
1115 \\
1099 \\
1068 \\
1035 \\
1047 \\
1063 \\
10884 \\
1099 \\
1130 \\
1120 \\
1124 \\
1076 \\
1107 \\
1091 \\
1083 \\
1066 \\
1116 \\
1037 \\
1085 \\
1060 \\
1071 \\
1074 \\
1161 \\
1125 \\
11186 \\
1219 \\
1206 \\
11156 \\
1076\end{array}$ & $\begin{array}{r}43 \\
27 \\
16 \\
21 \\
21 \\
12 \\
45 \\
49 \\
17 \\
19 \\
19 \\
9 \\
9 \\
12 \\
5 \\
36 \\
20 \\
17 \\
71 \\
41 \\
8 \\
23 \\
9 \\
18 \\
12 \\
38 \\
33 \\
20 \\
36 \\
43 \\
30 \\
20 \\
25 \\
1 \\
39 \\
15 \\
4 \\
9 \\
17 \\
21 \\
21 \\
11 \\
19 \\
14 \\
21 \\
28 \\
34 \\
4 \\
12 \\
12 \\
16 \\
51 \\
4 \\
20 \\
18 \\
26 \\
28 \\
27 \\
3 \\
14 \\
10 \\
9 \\
13 \\
16 \\
7 \\
4 \\
3 \\
44 \\
3 \\
15 \\
17 \\
8 \\
32 \\
34 \\
19 \\
10 \\
5 \\
10 \\
41 \\
43 \\
56 \\
64 \\
32\end{array}$ \\
\hline Log & $F_{4700}$ & & & & & & & -13 & \\
\hline
\end{tabular}




\begin{abstract}
APPENDIX B
Table 6 is the same as Table 5 except that the modified Julian date MJD and phase in the light cycle $\varphi$ are given instead of an MK spectral type. The modified Julian date equals the Julian date minus 2,440,000. The fluxes are listed for the Cepheids in order of increasing period and for each Cepheid in order of increasing phase.
\end{abstract}


TABLE 6

Observed Normalized Flux Distributions for the Cepheids

\begin{tabular}{|c|c|c|c|c|c|c|c|c|c|c|c|}
\hline & & & & & & & & & & DT & \\
\hline & & & & AR & & $\mathrm{BR}$ & & BR & & $\mathrm{HQ}$ & \\
\hline & & M.J.D. & 35.592 & 2,99 & & 3,42 & & 3,360 & & 3,43 & \\
\hline & & $\varphi 0$ & & & & & & & & & \\
\hline $\mathrm{N}$ & $\lambda$ & ${ }{ }_{\lambda} / F_{\lambda_{0}}$ & $\sigma$ & ${ }^{F}{ }_{\lambda} / F_{\lambda_{0}}$ & $\sigma$ & $\mathrm{F}_{\lambda} / \mathrm{F}_{\lambda_{0}}$ & $\sigma$ & ${ }^{F}{ }_{\lambda} /{ }_{\lambda_{0}}$ & $\sigma$ & $F_{\lambda} / F_{\lambda_{0}}$ & $\sigma$ \\
\hline $\begin{array}{l}1 \\
2\end{array}$ & $\begin{array}{l}3408 \\
3440\end{array}$ & $\begin{array}{l}276 \\
290\end{array}$ & 20 & $\begin{array}{l}293 \\
321\end{array}$ & $\begin{array}{r}10 \\
3\end{array}$ & 398 & 41 & 296 & 12 & 367 & 18 \\
\hline 3 & $\begin{array}{r}3440 \\
3472\end{array}$ & $\begin{array}{l}290 \\
267\end{array}$ & $\begin{array}{l}7 \\
4\end{array}$ & $\begin{array}{l}321 \\
291\end{array}$ & $\begin{array}{l}3 \\
7\end{array}$ & $\begin{array}{l}352 \\
337\end{array}$ & $\begin{array}{r}8 \\
13\end{array}$ & $\begin{array}{l}341 \\
312\end{array}$ & $\begin{array}{l}24 \\
40\end{array}$ & $\begin{array}{r}343 \\
304\end{array}$ & 23 \\
\hline 4 & 3503 & 258 & 9 & 372 & 31 & 320 & 8 & 321 & 10 & 337 & 19 \\
\hline 5 & $\begin{array}{r}3535 \\
3566\end{array}$ & $\begin{array}{l}293 \\
325\end{array}$ & $\begin{array}{l}5 \\
0\end{array}$ & $\begin{array}{l}360 \\
310\end{array}$ & 19 & $\begin{array}{r}353 \\
341\end{array}$ & 15 & 344 & 18 & 339 & $\begin{array}{r}10 \\
5\end{array}$ \\
\hline $\begin{array}{l}6 \\
7\end{array}$ & $\begin{array}{l}3566 \\
3598\end{array}$ & $\begin{array}{l}325 \\
264\end{array}$ & 100 & $\begin{array}{l}310 \\
310\end{array}$ & $\begin{array}{r}11 \\
3\end{array}$ & $\begin{array}{l}341 \\
342\end{array}$ & $\begin{array}{l}8 \\
9\end{array}$ & $\begin{array}{l}408 \\
379\end{array}$ & $\begin{array}{l}6 \\
0\end{array}$ & $\begin{array}{r}380 \\
352\end{array}$ & $\begin{array}{r}5 \\
14\end{array}$ \\
\hline 8 & 3629 & 288 & 11 & 299 & 6 & 378 & 5 & 401 & 16 & 346 & 3 \\
\hline 9 & 3661 & 313 & 12 & 386 & 18 & 397 & 27 & 409 & 13 & 404 & 4 \\
\hline $\begin{array}{l}10 \\
11\end{array}$ & 3692 & 313 & 13 & 409 & 34 & 457 & 6 & 465 & 10 & 434 & 20 \\
\hline $\begin{array}{l}11 \\
12\end{array}$ & 3724 & 396 & 22 & 423 & 25 & 473 & 9 & 533 & 5 & 506 & 6 \\
\hline $\begin{array}{l}12 \\
13\end{array}$ & $\begin{array}{l}3755 \\
3786\end{array}$ & 441 & 18 & 483 & 15 & 546 & 1 & 560 & 7 & 477 & 14 \\
\hline $\begin{array}{l}13 \\
14\end{array}$ & $\begin{array}{l}3786 \\
3818\end{array}$ & $\begin{array}{l}508 \\
587\end{array}$ & 8 & 559 & 5 & 603 & 23 & 646 & 11 & 602 & 25 \\
\hline $\begin{array}{l}14 \\
15\end{array}$ & $\begin{array}{r}3818 \\
3849\end{array}$ & $\begin{array}{l}587 \\
582\end{array}$ & $\begin{array}{r}9 \\
34\end{array}$ & $\begin{array}{l}614 \\
644\end{array}$ & $\begin{array}{r}6 \\
34\end{array}$ & $\begin{array}{l}556 \\
677\end{array}$ & $\begin{array}{r}6 \\
15\end{array}$ & 610 & 21 & 608 & 6 \\
\hline 16 & 3880 & 701 & 4 & 645 & $\begin{array}{r}34 \\
1\end{array}$ & 597 & $\begin{array}{r}15 \\
2\end{array}$ & $\begin{array}{l}608 \\
626\end{array}$ & $\begin{array}{r}31 \\
6\end{array}$ & $\begin{array}{l}577 \\
633\end{array}$ & $\begin{array}{l}15 \\
15\end{array}$ \\
\hline 17 & 3911 & 633 & 14 & 631 & 31 & 521 & 16 & 614 & 14 & 620 & 12 \\
\hline 18 & 3942 & 580 & 7 & 528 & 12 & 460 & 12 & 415 & 5 & 426 & 13 \\
\hline 19 & 3974 & 563 & 26 & 494 & 4 & 587 & 27 & 496 & 20 & 484 & 15 \\
\hline 20 & 4005 & 763 & 37 & 723 & 51 & 837 & 7 & 808 & 29 & 712 & 21 \\
\hline 21 & 4036 & 897 & 13 & 868 & 15 & 866 & 14 & 870 & 6 & 844 & 18 \\
\hline 22 & 4067 & 875 & 6 & 885 & 5 & 826 & 0 & 833 & 8 & 836 & 26 \\
\hline 23 & 4098 & 805 & 14 & 795 & 8 & 822 & 4 & 810 & 24 & 790 & 18 \\
\hline 24 & 4129 & 830 & 46 & 822 & 35 & 881 & 3 & 866 & 5 & 817 & 17 \\
\hline 25 & 4160 & 939 & 12 & 885 & 25 & 910 & 28 & 882 & 26 & 892 & 11 \\
\hline 26 & 4191 & 927 & 3 & 884 & 30 & 920 & 14 & 858 & 15 & 874 & 2 \\
\hline 27 & 4222 & 941 & 35 & 857 & 4 & 952 & 18 & 901 & 12 & 867 & 6 \\
\hline 28 & 4253 & 920 & 17 & 932 & 37 & 956 & 16 & 933 & 5 & 882 & 13 \\
\hline 29 & 4284 & 947 & 19 & 914 & 32 & 884 & 28 & 888 & 29 & 890 & 7 \\
\hline 30 & 4314 & 876 & 19 & 900 & 16 & 847 & 23 & 856 & 1 & 796 & 8 \\
\hline 31 & 4345 & 834 & 7 & 832 & 12 & 867 & 8 & 828 & 17 & 822 & 5 \\
\hline 32 & 4376 & 898 & 11 & 866 & 28 & 919 & 25 & 922 & 15 & 897 & 8 \\
\hline 33 & 4407 & 920 & 28 & 891 & 23 & 919 & 21 & 901 & 4 & 903 & \\
\hline 34 & 4438 & 923 & 3 & 905 & 17 & 940 & 21 & 925 & 12 & 898 & 11 \\
\hline 35 & 4468 & 945 & 24 & 887 & 18 & 960 & 5 & 937 & 11 & 908 & 14 \\
\hline 36 & 4499 & 962 & 11 & 921 & 30 & 987 & 13 & 988 & 4 & 952 & 23 \\
\hline 37 & 4530 & 995 & 5 & 956 & 2 & 955 & 4 & 962 & 42 & 974 & 17 \\
\hline 38 & 4560 & 972 & 7 & 948 & 26 & 974 & 13 & 952 & 9 & 937 & 8 \\
\hline 39 & 4591 & 965 & 13 & 939 & 9 & 996 & 5 & 976 & 16 & 964 & 5 \\
\hline 40 & 4621 & 955 & 46 & 957 & 17 & 993 & 18 & 1005 & 21 & 992 & 21 \\
\hline 41 & 4652 & 984 & 12 & 975 & 10 & 996 & 8 & 1000 & 35 & 999 & 16 \\
\hline 42 & 4682 & 1003 & 12 & 994 & 23 & 1011 & 2 & 989 & 23 & 985 & 3 \\
\hline 43 & 4713 & 1010 & 18 & 1006 & 1 & 972 & 7 & 994 & 15 & 1012 & 4 \\
\hline 44 & 4743 & 1002 & 2 & 1020 & 18 & 993 & 4 & 1017 & 24 & 1005 & \\
\hline 45 & 4774 & 1004 & 51 & 1014 & 26 & 1026 & 17 & 1027 & 8 & 996 & 6 \\
\hline 46 & 4804 & 1015 & 2 & 1031 & 10 & 1001 & 8 & 1034 & 15 & 1026 & 10 \\
\hline 47 & 4834 & 1040 & 20 & 1020 & 6 & 971 & 1 & 989 & 17 & 1003 & 14 \\
\hline 48 & 4865 & 909 & 9 & 945 & 22 & 878 & 9 & 919 & 16 & 903 & 2 \\
\hline 49 & 4895 & 942 & 42 & 914 & 6 & 965 & 9 & 953 & 17 & 892 & 22 \\
\hline 50 & 4925 & 960 & 17 & 940 & 1 & 969 & 8 & 996 & 13 & 972 & 20 \\
\hline 51 & 4956 & 1015 & 2 & 963 & 6 & 992 & 4 & 1017 & 15 & 993 & 19 \\
\hline 52 & 4986 & 976 & 6 & 959 & 22 & 925 & $i$ & 979 & 24 & 963 & 7 \\
\hline 53 & 5016 & 9.57 & 8 & 921 & 29 & 929 & 17 & 926 & 9 & 931 & 6 \\
\hline 54 & 5046 & 980 & 11 & 930 & 5 & 947 & 2 & 963 & 1 & 942 & 11 \\
\hline 55 & 5076 & 997 & 14 & 939 & 1 & 962 & 3 & 971 & 1 & 966 & 12 \\
\hline 56 & 5107 & 1027 & 15 & 928 & 6 & 927 & 12 & 968 & 21 & 955 & 20 \\
\hline 57 & 5137 & 1025 & 8 & 912 & 11 & 914 & 11 & 967 & 11 & 949 & 13 \\
\hline 58 & 5167 & 977 & 14 & 904 & 12 & 886 & 8 & 936 & 7 & 920 & 15 \\
\hline 59 & 5197 & 1023 & 22 & 889 & 1 & 879 & 2 & 915 & 23 & 892 & 13 \\
\hline 60 & 5227 & 1022 & 7 & 868 & 9 & 877 & 5 & 940 & 17 & 913 & 13 \\
\hline 61 & 5257 & 1025 & 2 & 862 & 11 & 903 & 17 & 944 & 15 & 908 & 20 \\
\hline 62 & 5287 & 994 & 13 & 849 & 6 & 895 & 17 & 921 & 12 & 904 & 6 \\
\hline 63 & 5317 & 998 & 30 & 850 & 18 & 908 & 15 & 922 & 7 & 951 & 7 \\
\hline 64 & 5347 & 981 & 11 & 886 & 13 & 879 & 19 & 891 & 17 & 936 & 4 \\
\hline 65 & 5377 & 988 & 9 & 878 & 7 & 876 & 21 & 875 & 7 & 977 & 9 \\
\hline 66 & 5406 & 933 & 8 & 827 & 13 & 840 & 16 & 848 & 27 & 969 & 10 \\
\hline 67 & 5436 & 940 & 25 & 826 & 12 & 894 & 9 & 852 & 34 & 950 & 7 \\
\hline 68 & 5466 & 972 & 3 & 811 & 15 & 893 & 13 & 852 & 18 & 938 & 21 \\
\hline 69 & 5496 & 970 & 27 & 844 & 8 & 837 & 0 & 824 & 5 & 960 & 29 \\
\hline 70 & 5526 & 910 & 18 & 825 & 13 & 814 & 15 & 802 & 2 & 950 & 15 \\
\hline 71 & 5555 & 959 & 2 & 839 & 1 & 851 & 31 & 789 & 4 & 947 & 8 \\
\hline 72 & 5585 & 923 & 18 & 909 & 25 & 806 & 43 & 803 & 32 & 946 & 9 \\
\hline 73 & 5615 & 950 & 34 & 907 & 24 & 795 & 57 & 794 & 6 & 916 & 16 \\
\hline 74 & 5645 & 942 & 19 & 827 & 6 & 767 & 11 & 799 & 5 & 908 & 22 \\
\hline 75 & 5674 & 914 & 23 & 814 & 59 & 781 & 30 & 820 & 7 & 914 & 45 \\
\hline 76 & 5704 & 959 & 19 & 811 & 8 & 772 & 22 & 807 & 4 & 905 & 30 \\
\hline 77 & 5733 & 997 & 5 & 802 & 15 & 803 & 41 & 820 & 38 & 919 & 28 \\
\hline 78 & 5763 & 1020 & 27 & 842 & 12 & 795 & 7 & 805 & 46 & 917 & 30 \\
\hline 79 & 5792 & 1038 & 5 & 866 & 29 & 846 & 44 & 839 & 5 & 915 & 14 \\
\hline 80 & 5822 & 1014 & 29 & 863 & 51 & 842 & 1 & 835 & 25 & 907 & 21 \\
\hline 81 & 5851 & 973 & 9 & 784 & 55 & 825 & 33 & 799 & 9 & 935 & 8 \\
\hline 82 & 5881 & 867 & 1 & 750 & 39 & 757 & 44 & 730 & 26 & 890 & 50 \\
\hline 83 & 5910 & 763 & 3 & 586 & 72 & 756 & 16 & 646 & 17 & 878 & 28 \\
\hline Log & $F_{4700}$ & -13 & & -13 & & -13 & & -13 & & -13 & \\
\hline & & & & & & & & & & & \\
\hline
\end{tabular}


TABLE 6-Continued

\begin{tabular}{|c|c|c|c|c|c|c|c|c|c|c|c|}
\hline & & & & & & DT & & DT & & DT & \\
\hline & & & & $\mathrm{AR}$ & & HR & & 盺 & & B R & \\
\hline & & M.J.D. & 3.658 & 2,99 & & 3,13 & & 2,97 & & 3,02 & \\
\hline & & 00 & & & & & & & & & \\
\hline $\mathrm{N}$ & $\lambda$ & ${ }^{F}{ }_{\lambda} / F_{\lambda_{0}}$ & $\sigma$ & $\mathrm{F}_{\lambda} / \mathrm{F}_{\lambda_{0}}$ & $\sigma$ & $\mathrm{F}_{\lambda} / \mathrm{F}_{\lambda_{0}}$ & $\sigma$ & $\mathrm{F}_{\lambda} / \mathrm{F}_{\lambda_{0}}$ & $\sigma$ & ${ }^{F}{ }_{\lambda} / F_{\lambda_{0}}$ & $\sigma$ \\
\hline $\begin{array}{l}1 \\
2\end{array}$ & 3408 & 296 & 38 & 373 & 27 & 311 & 12 & 309 & 21 & 421 & 30 \\
\hline 2 & 3440 & $\begin{array}{l}361 \\
363\end{array}$ & 33 & 384 & 47 & 316 & 29 & 335 & 30 & 366 & 43 \\
\hline 3 & 3472 & 333 & 19 & 312 & 41 & 328 & 28 & 287 & 16 & 395 & 26 \\
\hline 4 & $\begin{array}{l}3503 \\
3525\end{array}$ & 334 & 26 & 383 & 37 & 327 & 6 & 320 & 9 & 369 & 2 \\
\hline 5 & 3535 & 331 & 21 & 399 & 43 & 337 & 6 & 328 & 27 & 400 & 12 \\
\hline 6 & 3566 & 391 & 20 & 406 & 24 & 337 & 0 & 360 & 25 & 376 & 3 \\
\hline 7 & 3598 & 313 & 12 & 351 & 14 & 348 & 12 & 380 & 21 & 389 & 27 \\
\hline 8 & 3629 & 323 & 16 & 406 & 25 & 335 & 12 & 396 & 28 & 382 & 26 \\
\hline $10^{9}$ & 3661 & 398 & 17 & 417 & 43 & 395 & 13 & 378 & 43 & 432 & 20 \\
\hline $\begin{array}{l}10 \\
11\end{array}$ & $\begin{array}{l}3692 \\
3724\end{array}$ & 461 & 18 & 502 & 29 & 452 & 8 & 414 & 11 & 437 & 4 \\
\hline $\begin{array}{l}71 \\
12\end{array}$ & $\begin{array}{l}3724 \\
3755\end{array}$ & $\begin{array}{l}488 \\
481\end{array}$ & 36 & $\begin{array}{l}500 \\
503\end{array}$ & 18 & 501 & 1 & 492 & 2 & 478 & 12 \\
\hline 13 & 3786 & $\begin{array}{l}487 \\
531\end{array}$ & 26 & $\begin{array}{l}603 \\
638\end{array}$ & $\begin{array}{l}30 \\
27\end{array}$ & $\begin{array}{l}567 \\
592\end{array}$ & 3 & $\begin{array}{l}522 \\
615\end{array}$ & 19 & 497 & 12 \\
\hline 14 & 3818 & 607 & 26 & 659 & 14 & 599 & 4 & 697 & 13 & 628 & 18 \\
\hline 15 & 3849 & 623 & 15 & 723 & 20 & 657 & 12 & 694 & 31 & 661 & $\begin{array}{l}32 \\
28\end{array}$ \\
\hline 16 & 3880 & 653 & 32 & 641 & 8 & 599 & 16 & 682 & 25 & 668 & 11 \\
\hline 17 & 3911 & 593 & 46 & 616 & 26 & 510 & 1 & 651 & 16 & 639 & 7 \\
\hline 18 & 3942 & 432 & 31 & 541 & 30 & 545 & 21 & 550 & 14 & 498 & 11 \\
\hline 19 & 3974 & 489 & 23 & 641 & 40 & 725 & 25 & 576 & 22 & 543 & 2 \\
\hline 20 & 4005 & 816 & 31 & 898 & 30 & 845 & 9 & 868 & 21 & 834 & 11 \\
\hline 21 & 4036 & 853 & 21 & 916 & 19 & 862 & 5 & 916 & 8 & 910 & 20 \\
\hline 22 & 4067 & 845 & 16 & 900 & 14 & 818 & $?$ & 874 & 23 & 884 & 14 \\
\hline 23 & 4098 & 770 & 20 & 840 & 31 & 847 & 1 & 809 & 14 & 786 & 4 \\
\hline 24 & 4129 & 845 & 12 & 943 & 31 & 906 & 12 & 882 & 18 & 874 & 27 \\
\hline 25 & 4160 & 898 & 23 & 932 & 6 & 885 & 12 & 905 & 7 & 924 & 13 \\
\hline $\begin{array}{l}26 \\
27\end{array}$ & $\begin{array}{l}4191 \\
4222\end{array}$ & $\begin{array}{l}891 \\
897\end{array}$ & 21 & 957 & 26 & 888 & 16 & 869 & 26 & 898 & 16 \\
\hline 28 & 4253 & $\begin{array}{l}897 \\
924\end{array}$ & $\begin{array}{l}12 \\
23\end{array}$ & $\begin{array}{l}963 \\
981\end{array}$ & $\begin{array}{l}28 \\
19\end{array}$ & $\begin{array}{l}923 \\
922\end{array}$ & $\begin{array}{l}y \\
6\end{array}$ & $\begin{array}{l}827 \\
857\end{array}$ & $\begin{array}{l}25 \\
19\end{array}$ & $\begin{array}{l}926 \\
953\end{array}$ & 2 \\
\hline 29 & 4284 & 885 & 26 & 886 & 32 & 876 & 23 & 845 & 15 & 908 & 21 \\
\hline 30 & 4314 & 839 & 29 & 936 & 14 & 853 & 46 & 820 & 27 & 871 & 18 \\
\hline 31 & 4345 & 819 & 32 & 890 & 33 & 918 & 39 & 769 & 4 & 798 & 15 \\
\hline 32 & 4376 & 929 & 24 & 947 & 11 & 941 & 42 & 900 & 22 & 919 & $=$ \\
\hline 33 & 4407 & 879 & 18 & 926 & 22 & 934 & 24 & 894 & 15 & 902 & $=$ \\
\hline 34 & 4438 & 958 & 12 & 942 & 8 & 953 & 23 & 883 & 13 & 960 & 20 \\
\hline 35 & 4468 & 906 & 24 & 991 & 6 & 996 & 23 & 913 & 29 & 906 & 5 \\
\hline 36 & 4499 & 988 & 30 & 1040 & 13 & 1004 & 36 & 984 & 39 & 977 & 14 \\
\hline 37 & $\begin{array}{l}4530 \\
4560\end{array}$ & $\begin{array}{l}957 \\
969\end{array}$ & 21 & $\begin{array}{r}935 \\
995\end{array}$ & $2_{1}^{4}$ & $\begin{array}{r}950 \\
925\end{array}$ & 49 & 924 & $\begin{array}{r}4 \\
25\end{array}$ & 962 & 20 \\
\hline 38 & $\begin{array}{l}4560 \\
4501\end{array}$ & 969 & 10 & 995 & 21 & 925 & 64 & 976 & 25 & 952 & 19 \\
\hline 39 & 4591 & 943 & 17 & 999 & 28 & 980 & 24 & 945 & 24 & 963 & 20 \\
\hline 40 & 4621 & 1044 & 28 & 1028 & 28 & 1006 & 3 & 990 & 37 & 1007 & 13 \\
\hline 41 & 4652 & 990 & 16 & 944 & 24 & 1011 & 9 & 999 & 28 & 997 & 10 \\
\hline 42 & 4682 & 1000 & 21 & 1008 & 12 & 1011 & 2 & 1009 & 10 & 1001 & 26 \\
\hline $\begin{array}{l}43 \\
44\end{array}$ & $\begin{array}{l}4713 \\
4743\end{array}$ & $\begin{array}{r}984 \\
1028\end{array}$ & 10 & 1001 & 15 & 992 & 6 & 982 & 14 & 1014 & 1 \\
\hline $\begin{array}{l}44 \\
45\end{array}$ & $\begin{array}{l}4743 \\
4774\end{array}$ & $\begin{array}{r}1028 \\
995\end{array}$ & $\begin{array}{l}10 \\
12\end{array}$ & $\begin{array}{l}1040 \\
1009\end{array}$ & $\begin{array}{r}13 \\
8\end{array}$ & $\begin{array}{r}988 \\
979\end{array}$ & $\begin{array}{l}10 \\
28\end{array}$ & $\begin{array}{l}1011 \\
1010\end{array}$ & $\begin{array}{l}13 \\
22\end{array}$ & $\begin{array}{r}990 \\
986\end{array}$ & 17 \\
\hline 46 & 4804 & 1039 & 14 & 1031 & 17 & 975 & 37 & 1019 & 18 & 988 & 3 \\
\hline 47 & 4834 & 951 & 7 & 969 & 12 & 943 & 53 & 963 & 9 & 989 & 38 \\
\hline 48 & 4865 & 887 & 10 & 908 & 34 & 881 & 21 & 870 & 5 & 842 & 17 \\
\hline 49 & 4895 & 939 & 24 & 938 & 31 & 943 & 5 & 916 & 18 & 899 & 16 \\
\hline 50 & 4925 & 979 & 19 & 989 & 16 & 934 & 40 & 981 & 29 & 929 & 12 \\
\hline 51 & 4956 & 998 & 30 & 985 & 6 & 920 & 10 & 1027 & 20 & 952 & 6 \\
\hline 52 & $\begin{array}{l}4986 \\
5015\end{array}$ & 989 & 31 & 941 & 12 & 907 & 3 & 947 & 32 & 907 & 17 \\
\hline 53 & 5016 & 922 & 24 & 893 & 28 & 927 & 23 & 871 & 15 & 841 & 18 \\
\hline 54 & 5046 & 932 & 3 & 925 & 13 & 989 & 38 & 942 & 11 & 860 & 17 \\
\hline 55 & 5076 & 932 & 17 & 940 & 16 & 1030 & 40 & 916 & 15 & 853 & 22 \\
\hline 56 & 5107 & 955 & 27 & 932 & 16 & 1001 & 25 & 931 & 24 & 841 & 9 \\
\hline 57 & 5137 & 900 & 23 & 927 & 14 & 954 & 24 & 882 & 30 & 834 & 24 \\
\hline 58 & 5167 & 906 & 44 & 910 & 7 & 947 & 3 & 859 & 20 & 808 & 19 \\
\hline 59 & 5197 & 870 & 21 & 887 & 7 & 963 & 19 & 854 & 12 & 819 & 7 \\
\hline 60 & 5227 & 907 & 24 & 915 & 3 & 995 & 1 & 884 & 10 & 822 & 2 \\
\hline 61 & 5257 & 894 & 11 & 871 & 10 & 946 & 29 & 847 & 21 & 811 & 3 \\
\hline 62 & 5287 & 891 & 22 & 849 & 27 & 970 & 9 & 865 & 36 & 836 & 7 \\
\hline 63 & 5317 & 894 & 7 & 879 & 25 & 969 & 23 & 831 & 32 & 817 & 29 \\
\hline 64 & 5347 & 906 & 22 & 877 & 24 & 974 & 22 & 842 & 27 & 804 & 30 \\
\hline 65 & 5377 & 880 & 10 & 850 & 3 & 936 & 27 & 856 & 19 & 818 & 17 \\
\hline 66 & 5406 & 841 & 18 & 840 & 12 & 940 & 6 & 872 & 15 & 788 & 6 \\
\hline 67 & 5436 & 880 & 26 & 864 & 20 & 971 & 18 & 883 & 11 & 781 & 5 \\
\hline 68 & 5466 & 901 & 45 & 868 & 17 & 910 & 29 & 883 & 13 & 803 & 6 \\
\hline 69 & 5496 & 829 & 28 & 835 & 12 & 978 & 36 & 852 & 5 & 783 & 5 \\
\hline 70 & 5526 & 849 & 21 & 842 & 18 & 944 & 6 & 822 & 16 & $\begin{array}{l}752 \\
735\end{array}$ & 15 \\
\hline 71 & 5555 & 848 & 47 & 905 & 12 & 921 & 54 & 803 & 25 & 735 & 27 \\
\hline 72 & 5585 & 850 & 73 & 876 & 14 & 932 & 59 & 789 & 21 & 747 & 45 \\
\hline 73 & 5615 & 858 & 34 & 899 & 35 & 1014 & 25 & 806 & 24 & 772 & 40 \\
\hline 74 & 5645 & 888 & 53 & 869 & 33 & 939 & 13 & 799 & 50 & 746 & 3 \\
\hline 75 & 5674 & 794 & 15 & 858 & 21 & 873 & 3 & 815 & 39 & 695 & 13 \\
\hline 76 & 5704 & 754 & 31 & 863 & 22 & 927 & 38 & 779 & 34 & 681 & 16 \\
\hline 77 & 5733 & 812 & 34 & 866 & 40 & 975 & 15 & 877 & 13 & 707 & 12 \\
\hline 78 & 5763 & 873 & 34 & 744 & 56 & 955 & 22 & 849 & 11 & 703 & 22 \\
\hline 79 & 5792 & 885 & $\begin{array}{l}30 \\
52\end{array}$ & 805 & 37 & $\begin{array}{r}978 \\
\end{array}$ & 13 & 826 & $\begin{array}{r}30 \\
27\end{array}$ & 668 & 31 \\
\hline 80 & 5822 & 869 & 53 & 877 & 32 & 1019 & 11 & 723 & 27 & 664 & 21 \\
\hline 81 & 5851 & 787 & 6 & 857 & 29 & 1005 & 23 & 801 & 62 & 622 & 30 \\
\hline 82 & 5881 & 734 & 20 & 752 & 39 & 886 & 7 & 766 & 65 & 512 & 8 \\
\hline 83 & 5910 & 605 & 47 & 694 & 30 & 786 & 11 & 895 & 43 & 481 & 38 \\
\hline Log & $F_{4700}$ & & & & & -13 & & -13 & & & \\
\hline & & & & & & & & & & & \\
\hline
\end{tabular}


TABLE 6-Continued

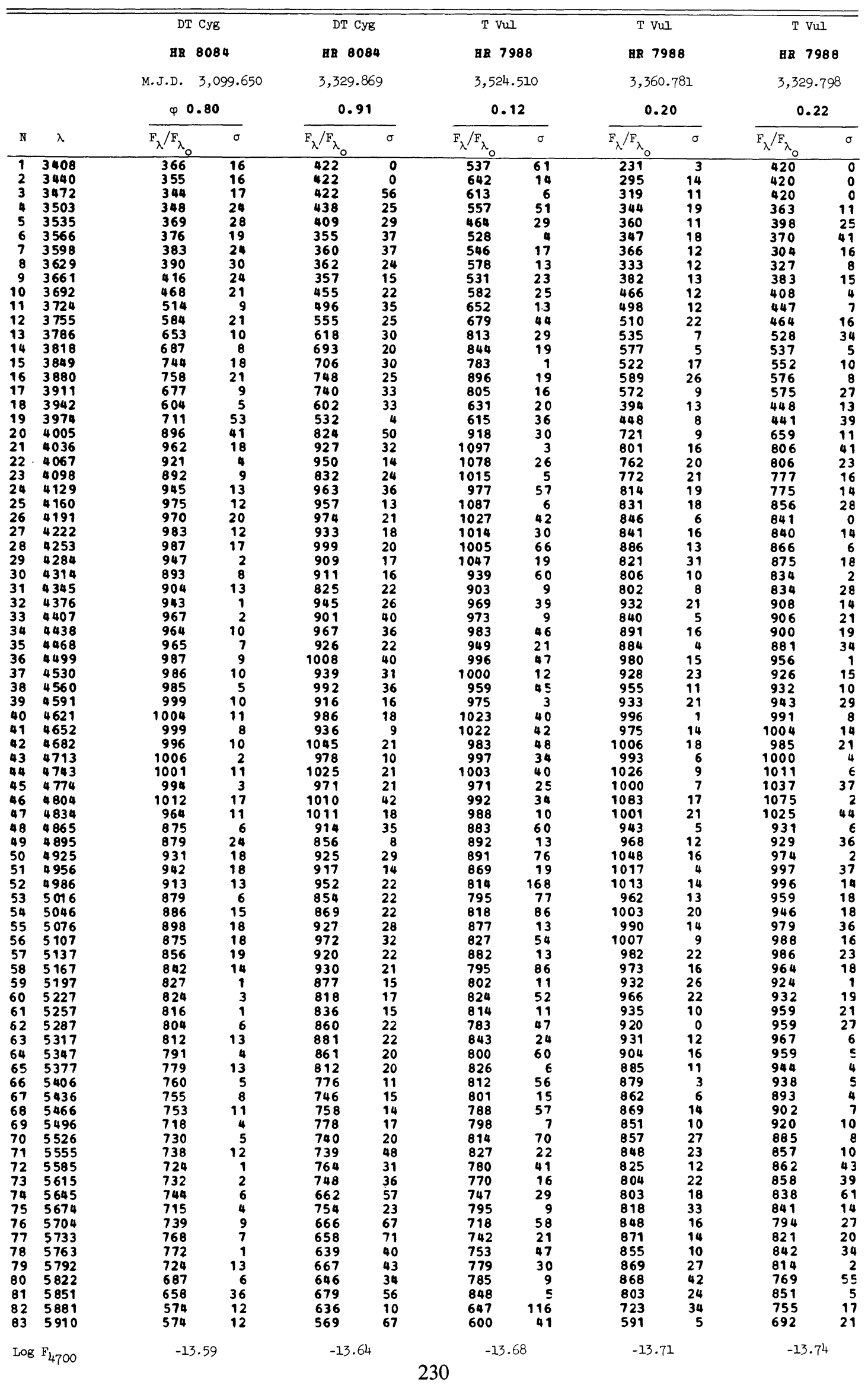


TABLE 6-Continued

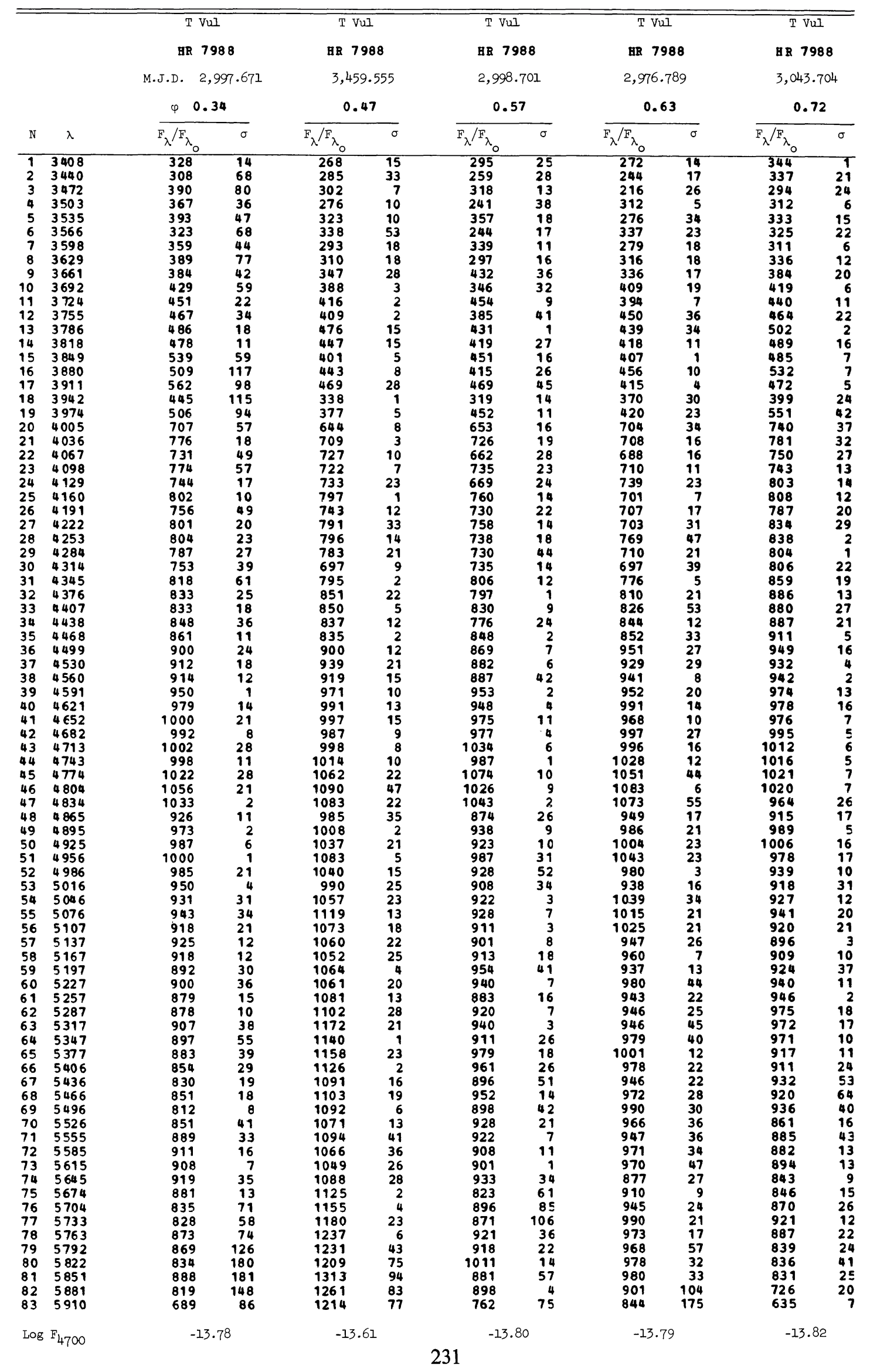


TABLE 6-Continued

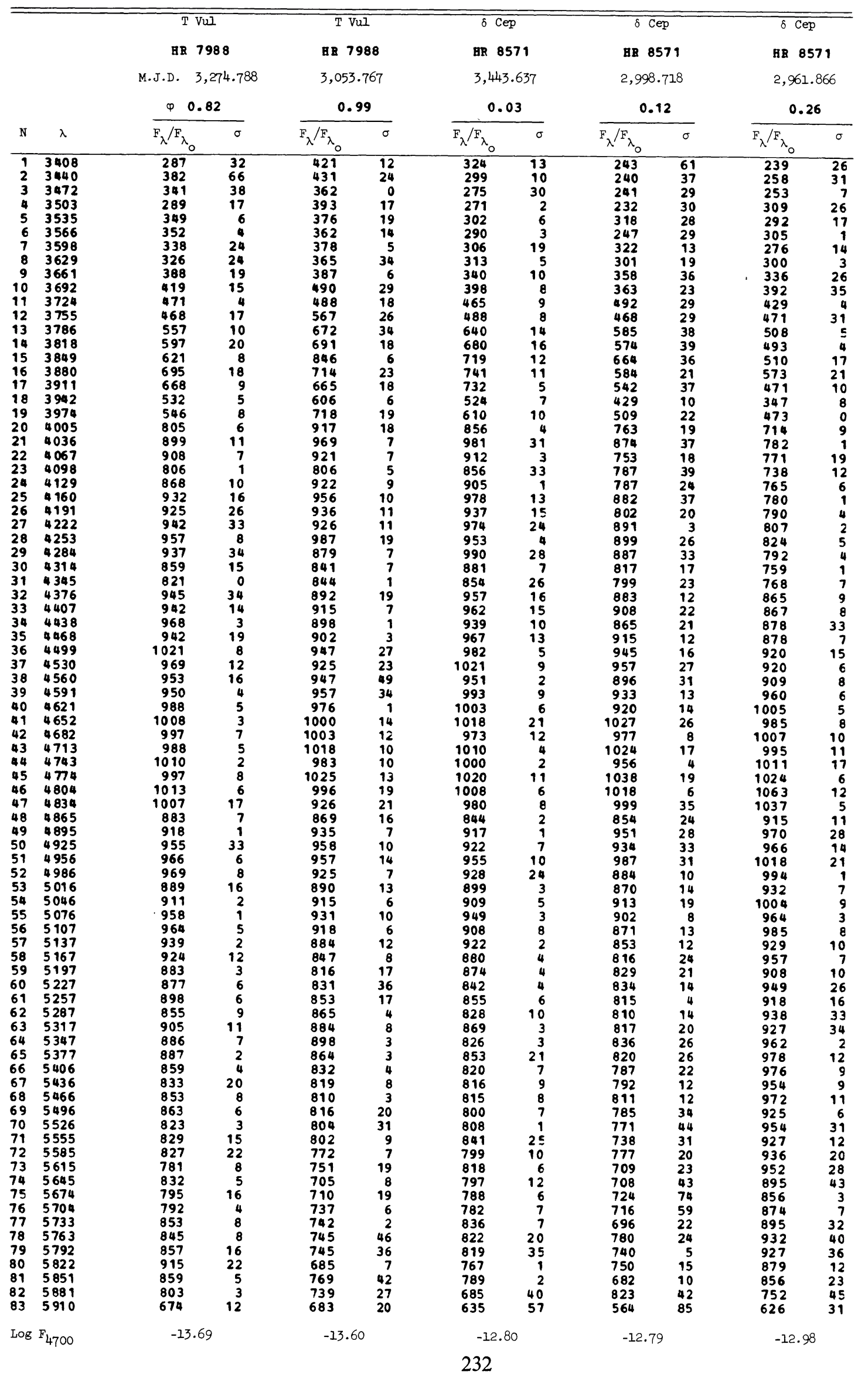


TABLE 6-Continued

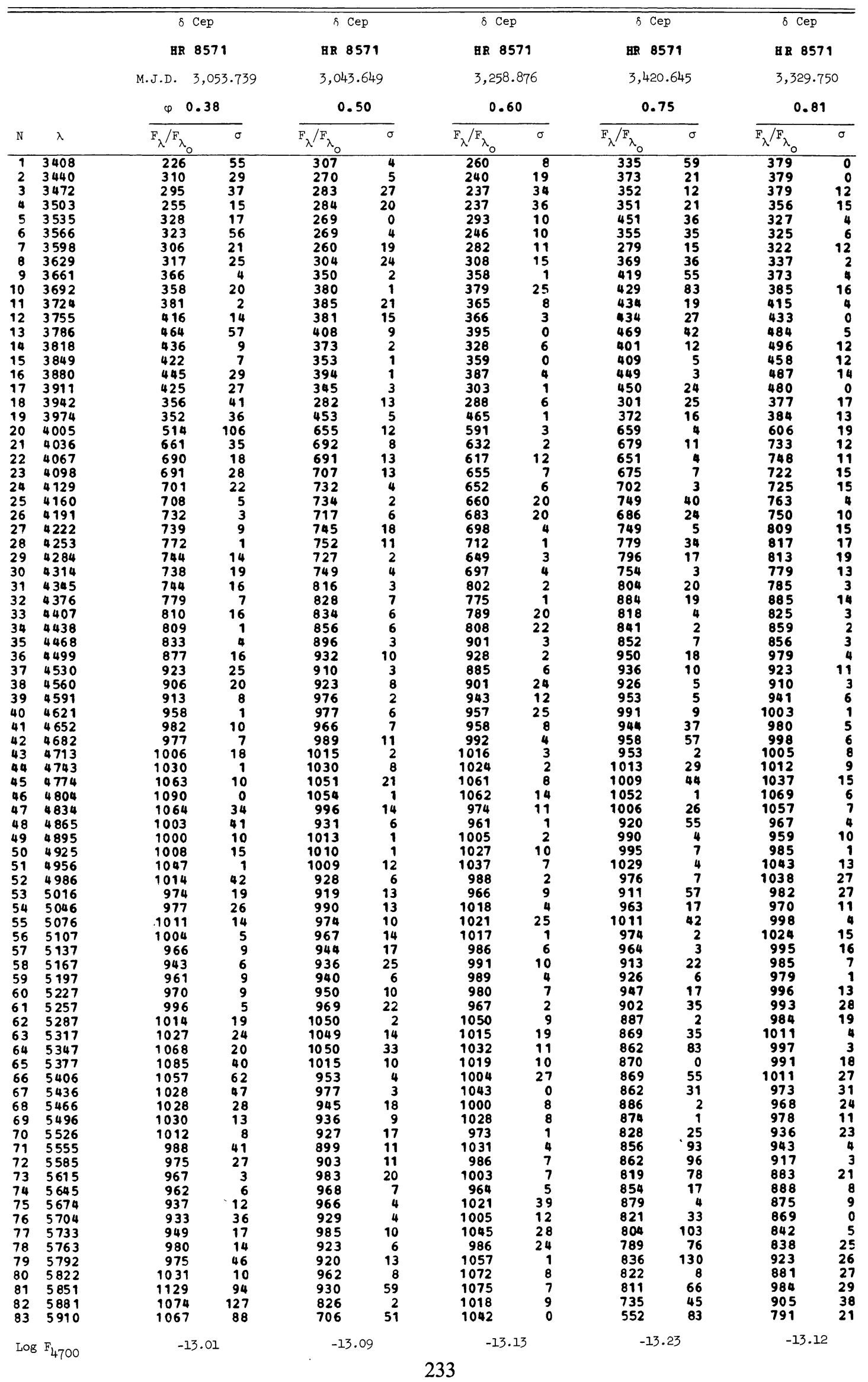


TABLE 6-Continued

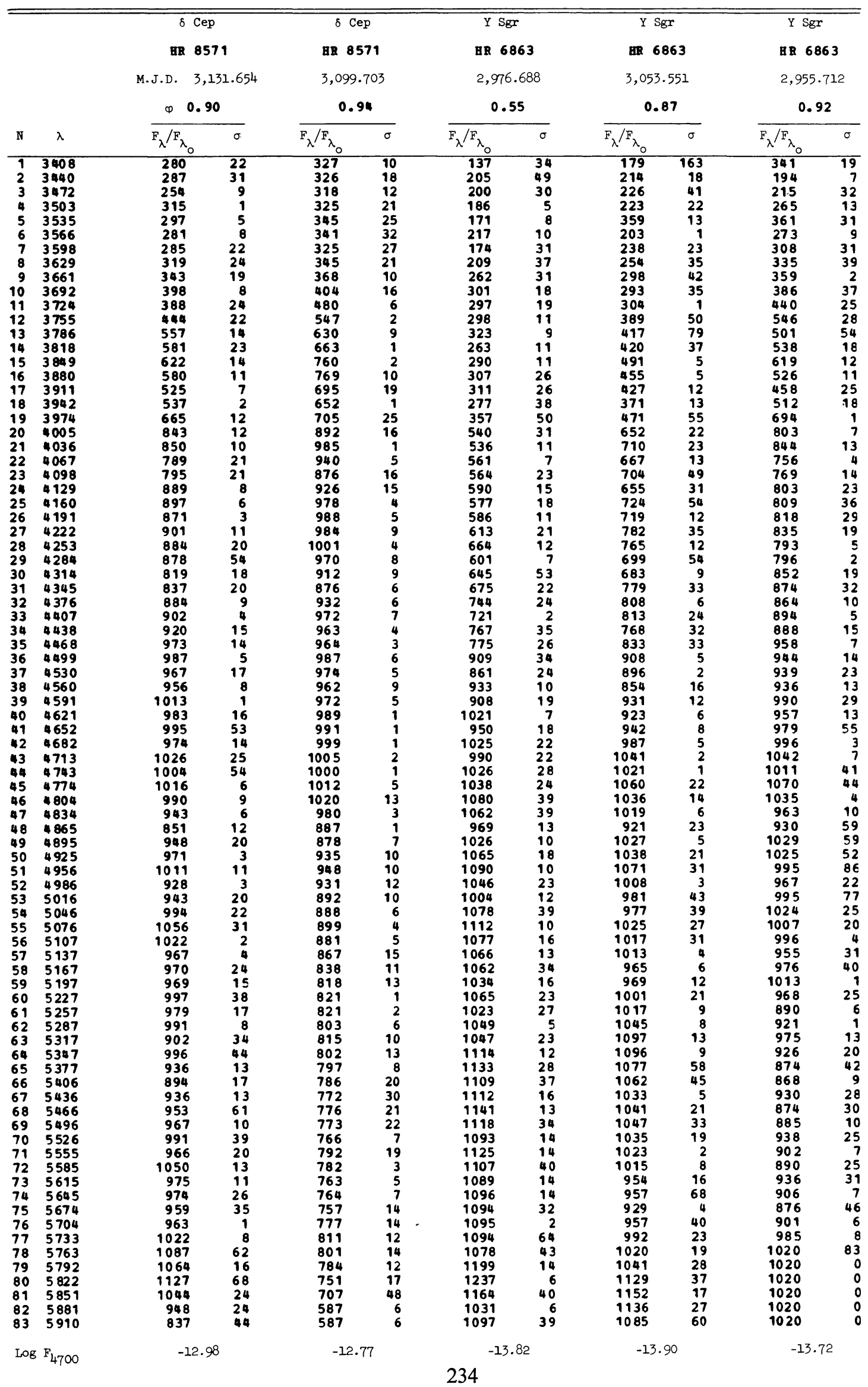


TABLE 6-Continued

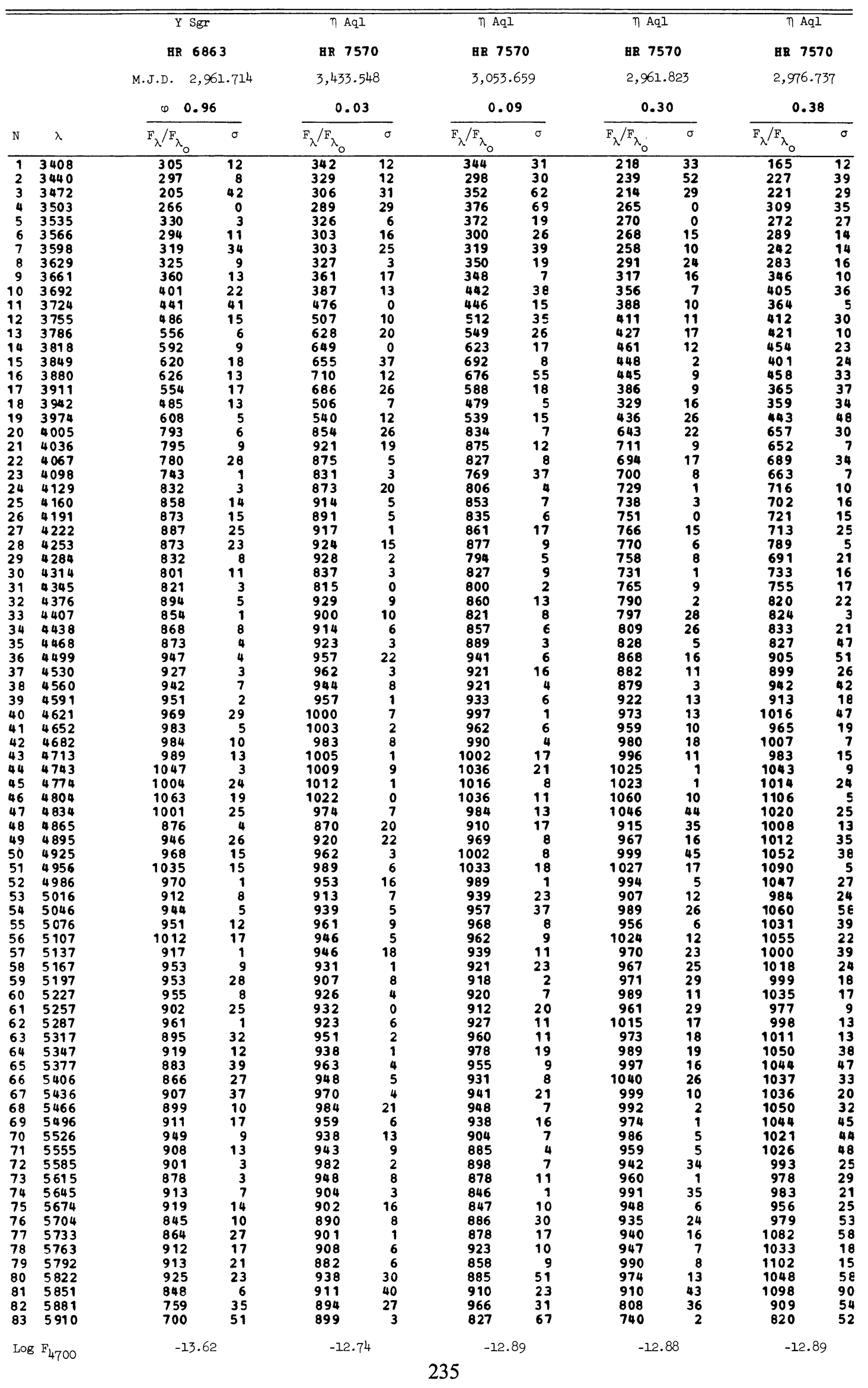


TABLE 6-Continued

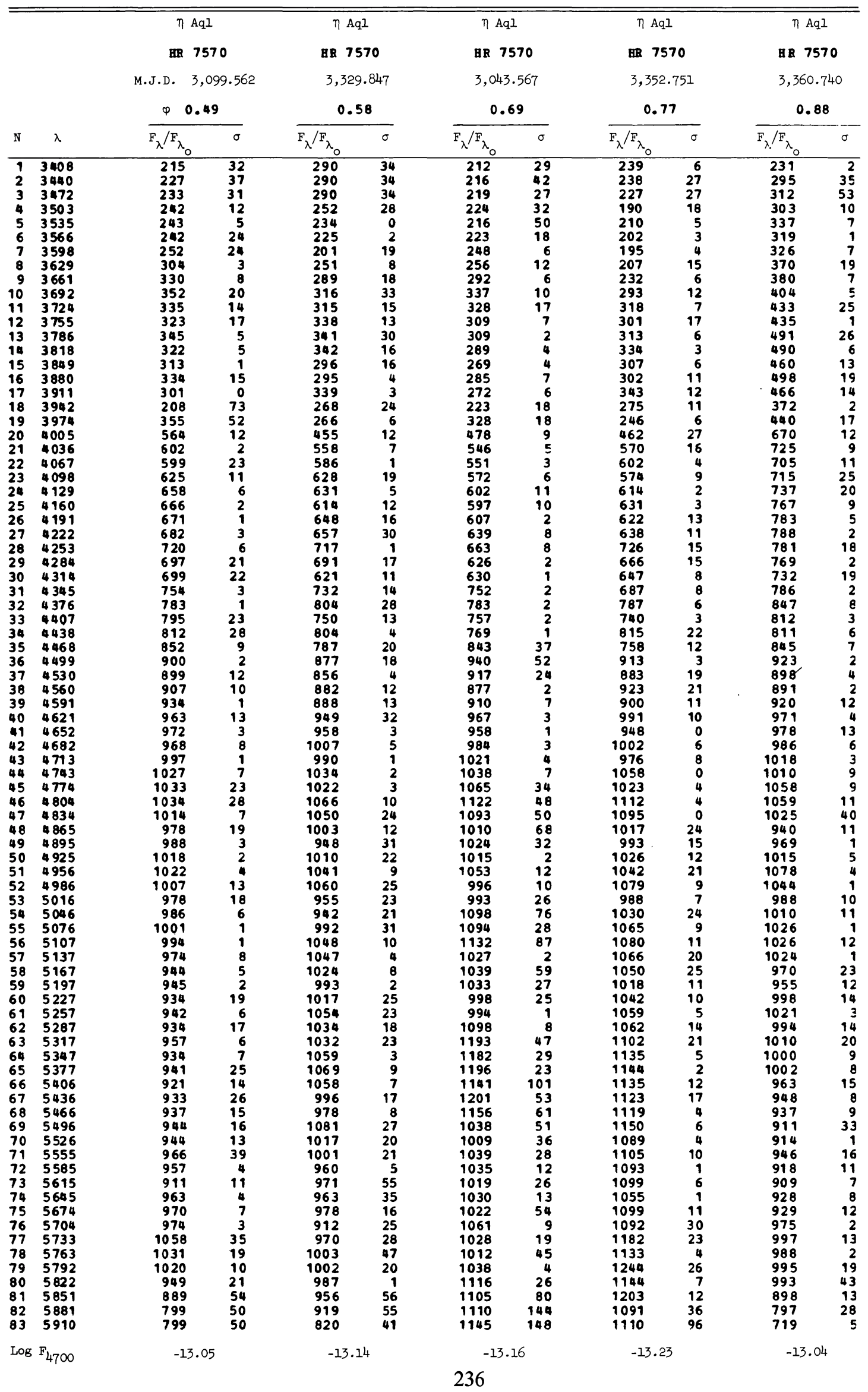


TABLE 6-Continued

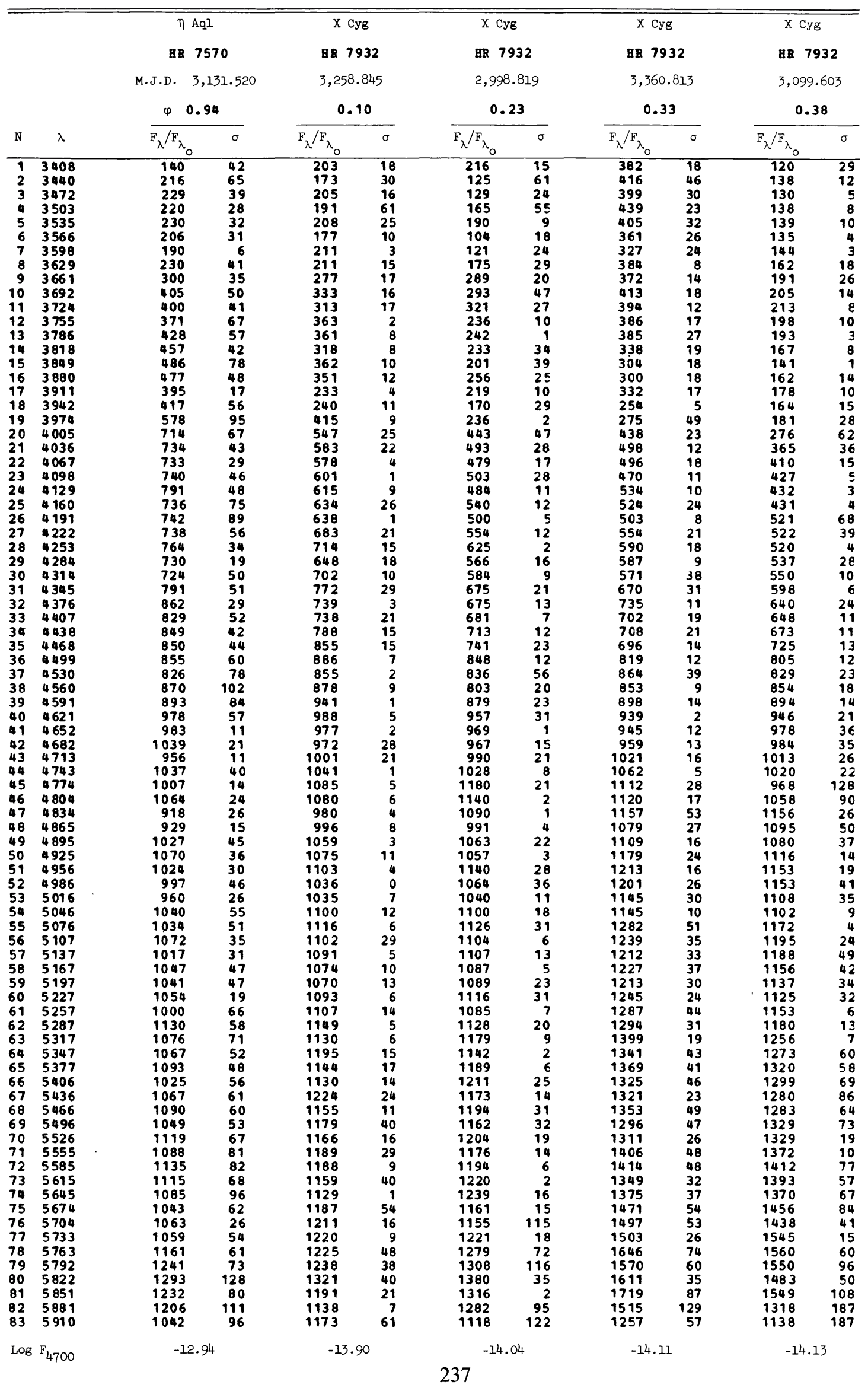


TABLE 6-Continued

\begin{tabular}{|c|c|c|c|c|c|c|c|c|c|c|}
\hline & & & & $\mathrm{x}$ & & $\mathrm{x}$ & & $\mathrm{x}$ & & $\mathrm{x}$ \\
\hline & & HR & & HR & & $\mathrm{BR}$ & & QRR & & BR \\
\hline & & M.J.D. & 51.601 & 3,05 & & 3,44 & & 3,4 & & 3,3 \\
\hline & & $\varphi 0$ & & & & & & & & \\
\hline $\mathrm{N}$ & $\lambda$ & $F_{\lambda} / F_{\lambda_{0}}$ & $\sigma$ & ${ }^{F_{\lambda}} / F_{\lambda_{0}}$ & $\sigma$ & $\mathrm{F}_{\lambda} / \mathrm{F}_{\lambda_{0}}$ & $\sigma$ & $\mathrm{F}_{\lambda} / \mathrm{F}_{\lambda_{0}}$ & $\sigma$ & $\mathrm{F}_{\lambda} / \mathrm{F}_{\lambda_{0}}$ \\
\hline 1 & 3408 & 76 & 10 & 121 & 46 & 78 & 20 & 143 & 34 & 119 \\
\hline 2 & 3440 & 107 & 10 & 165 & 39 & 110 & 2 & 201 & 36 & 146 \\
\hline 3 & 3472 & 112 & 11 & 128 & 37 & 93 & 36 & 150 & 13 & 157 \\
\hline 4 & 3503 & 103 & 5 & 68 & 67 & 122 & 17 & 190 & 57 & 167 \\
\hline 5 & 3535 & 108 & 1 & 114 & 30 & 103 & 2 & 194 & 3 & 177 \\
\hline 6 & 3566 & 105 & 2 & 102 & 22 & 101 & $2 \overline{2}$ & 180 & 18 & 178 \\
\hline $\begin{array}{l}7 \\
8\end{array}$ & $\begin{array}{l}3598 \\
3629\end{array}$ & $\begin{array}{l}128 \\
121\end{array}$ & $\begin{array}{l}18 \\
11\end{array}$ & $\begin{array}{r}90 \\
143\end{array}$ & 15 & 115 & $\begin{array}{l}3 \\
5\end{array}$ & $\begin{array}{l}151 \\
189\end{array}$ & 27 & 168 \\
\hline 9 & 3661 & 125 & 26 & 187 & 25 & 189 & 16 & 217 & $\begin{array}{l}13 \\
13\end{array}$ & $\begin{array}{r}185 \\
201\end{array}$ \\
\hline 10 & 3692 & 154 & 33 & 144 & 8 & 184 & 11 & 266 & 1 & 220 \\
\hline & 3724 & 168 & 29 & 177 & 1 & 157 & 12 & 238 & 5 & 254 \\
\hline 12 & 3755 & 171 & 1 & 180 & 1 & 159 & 27 & 246 & 27 & 262 \\
\hline 13 & 3786 & 179 & 16 & 197 & 12 & 183 & 23 & 247 & 13 & 246 \\
\hline 14 & 3818 & 150 & 5 & 124 & 29 & 125 & 8 & 261 & 28 & 243 \\
\hline 15 & 3849 & 144 & 33 & 121 & 1 & 122 & 1 & 210 & 18 & 232 \\
\hline 16 & 3880 & 131 & 13 & 129 & 3 & 160 & 18 & 248 & 20 & 242 \\
\hline 17 & 3911 & 142 & 1 & 163 & 3 & 167 & 18 & 277 & 14 & 289 \\
\hline 18 & 3942 & 116 & 12 & 134 & 13 & 131 & 20 & 219 & 4 & 212 \\
\hline 19 & 3974 & 158 & 1 & 165 & 7 & 171 & 9 & 230 & 6 & 220 \\
\hline 20 & 4005 & 191 & 54 & 313 & 18 & 320 & 9 & 371 & 18 & 347 \\
\hline 21 & 4036 & 239 & 76 & 349 & 9 & 361 & 16 & 470 & 19 & 454 \\
\hline 22 & 4067 & 286 & 66 & 356 & 1 & 336 & 6 & 510 & 9 & 460 \\
\hline 23 & 4098 & 360 & 8 & 408 & 8 & 414 & 16 & 454 & 10 & 489 \\
\hline 24 & 4129 & 355 & 15 & 360 & 21 & 378 & 2 & 505 & 13 & 486 \\
\hline $\begin{array}{l}25 \\
25\end{array}$ & $\begin{array}{l}4160 \\
4191\end{array}$ & $\begin{array}{l}368 \\
371\end{array}$ & 9 & $\begin{array}{r}354 \\
396\end{array}$ & 6 & 396 & 5 & 511 & 15 & 512 \\
\hline $\begin{array}{l}26 \\
27\end{array}$ & $\begin{array}{l}4191 \\
4222\end{array}$ & 339 & 58 & $\begin{array}{l}396 \\
437\end{array}$ & $\begin{array}{l}10 \\
10\end{array}$ & $\begin{array}{l}401 \\
495\end{array}$ & $\begin{array}{l}5 \\
7\end{array}$ & $\begin{array}{l}555 \\
542\end{array}$ & 2 & $\begin{array}{l}529 \\
533\end{array}$ \\
\hline 28 & 4253 & 426 & 34 & 487 & 8 & 514 & 4 & 586 & 6 & 585 \\
\hline 29 & 4284 & 476 & 20 & 433 & 18 & 491 & 5 & 587 & 30 & 605 \\
\hline 30 & 4314 & 481 & 17 & 522 & 2 & 514 & 21 & 569 & 8 & 542 \\
\hline 39 & 4345 & 561 & 18 & 633 & 3 & 637 & 15 & 670 & 6 & 633 \\
\hline 32 & 4376 & 580 & 88 & 618 & 19 & 635 & 9 & 768 & 5 & 719 \\
\hline 33 & 4407 & 616 & 3 & 621 & 1 & 610 & 11 & 656 & 14 & 689 \\
\hline 34 & 4438 & 642 & 6 & 619 & 12 & 654 & 22 & 700 & 9 & 684 \\
\hline 35 & 4468 & 652 & 34 & 652 & 16 & 702 & 10 & 677 & 24 & 715 \\
\hline 36 & 4499 & 719 & 68 & 813 & 1 & 824 & 11 & 830 & 33 & 825 \\
\hline 37 & 4530 & 749 & 63 & 766 & 17 & 811 & 2 & 826 & 7 & 833 \\
\hline 38 & 4560 & 792 & 51 & 827 & 10 & 804 & 20 & 824 & 24 & 854 \\
\hline 39 & 4591 & 896 & 57 & 872 & 4 & 873 & 35 & 850 & 8 & 854 \\
\hline 40 & 4621 & 894 & 63 & 959 & 4 & 987 & 23 & 946 & 28 & 934 \\
\hline 41 & 4652 & 970 & 25 & 951 & 4 & 962 & 8 & 948 & 15 & 966 \\
\hline 42 & 4682 & $\begin{array}{r}960 \\
1029\end{array}$ & 27 & 963 & 4 & 956 & 1 & 964 & 4 & 1002 \\
\hline 43 & 4713 & 1029 & $\begin{array}{l}71 \\
75\end{array}$ & 1000 & 23 & 1004 & 23 & 1018 & 18 & 983 \\
\hline 44 & 4743 & 1030 & 75 & 1069 & 24 & 1069 & 14 & 1064 & 1 & 1038 \\
\hline 45 & 4774 & 1093 & 42 & 1181 & 51 & 1124 & 42 & 1051 & 11 & 1051 \\
\hline 46 & 4804 & 1126 & 50 & 1156 & 25 & 1163 & 32 & 1129 & 20 & 1093 \\
\hline 47 & 4834 & 1213 & 10 & 1147 & 37 & 1102 & 8 & 1115 & 21 & 1116 \\
\hline 48 & 4865 & 1151 & 50 & 1059 & 28 & 1029 & 2 & 1067 & 9 & 1032 \\
\hline 49 & 4895 & 1193 & 115 & 1172 & 18 & 1107 & $\overline{3}$ & 986 & 14 & 995 \\
\hline 50 & 4925 & 1228 & 32 & 1212 & 50 & 1162 & 29 & 1103 & 6 & 1034 \\
\hline 51 & 4956 & 1154 & 10 & 1297 & 63 & 1217 & 3 & 1112 & 38 & 1101 \\
\hline 52 & 4986 & 1180 & 59 & 1161 & 41 & 1140 & 31 & 1167 & 26 & 1146 \\
\hline 53 & 5016 & 1197 & 91 & 1113 & 34 & 1086 & 31 & 1030 & 1 & 1070 \\
\hline 54 & 5046 & 1236 & 16 & 1250 & 45 & 1206 & 19 & 1112 & 20 & 1053 \\
\hline 55 & 5076 & .1282 & 12 & 1275 & 18 & 1213 & 9 & 1175 & 5 & 1150 \\
\hline 56 & 5107 & 1262 & 69 & 1215 & 24 & 1182 & 4 & 1187 & 36 & 1164 \\
\hline 57 & 5137 & 1361 & 95 & 1179 & 31 & 1155 & 8 & 1134 & 27 & 1167 \\
\hline 58 & 5167 & 1354 & 8 & 1188 & 20 & 1133 & 9 & 1156 & 6 & 1146 \\
\hline 59 & 5197 & 1302 & 89 & 1231 & 16 & 1195 & 25 & 1117 & 14 & 1093 \\
\hline 60 & 5227 & 1331 & 38 & 1269 & 5 & 1207 & 4 & 1155 & 26 & 1099 \\
\hline 61 & 5257 & 1397 & 75 & 1268 & 25 & 1230 & 52 & 1190 & 20 & 1146 \\
\hline 62 & 5287 & 1423 & 24 & 1332 & 28 & 1247 & 13 & 1252 & 57 & 1169 \\
\hline 63 & 5317 & 1569 & 67 & 1466 & 7 & 1356 & 9 & 1331 & 18 & 1262 \\
\hline 64 & 5347 & 1466 & 50 & 1551 & 29 & 1360 & 23 & 1325 & 35 & 1304 \\
\hline 65 & 5377 & 1730 & 143 & 1561 & 44 & 9410 & 30 & 1348 & 24 & 1261 \\
\hline 66 & 5406 & 1632 & 93 & 1492 & 34 & 1318 & 1 & 1408 & 8 & 1305 \\
\hline 67 & 5436 & 1715 & 213 & 1465 & 40 & 1416 & 33 & 1388 & 20 & 1297 \\
\hline 68 & 5466 & 1675 & 23 & 1501 & 62 & 1454 & 23 & 1485 & 29 & 1299 \\
\hline 69 & 5496 & 1629 & 81 & 1513 & 51 & 1442 & 43 & 1483 & 9 & 1310 \\
\hline 70 & 5526 & 1663 & 13 & 1535 & 7 & 1403 & 29 & 1502 & 4 & 1277 \\
\hline 71 & 5555 & 1736 & 171 & 1550 & 61 & 1477 & 46 & 1474 & 40 & 1293 \\
\hline 72 & 5585 & 1692 & 54 & 1591 & 87 & 1474 & 71 & 1534 & 4 & 1305 \\
\hline 73 & 5615 & 1752 & 170 & 1525 & 5 & 1526 & 73 & 1453 & 23 & 1325 \\
\hline 74 & 5645 & 1720 & 81 & 1501 & 45 & 1469 & 57 & 1562 & 24 & 1314 \\
\hline 75 & 5674 & 1856 & 132 & 1519 & 14 & 1459 & 49 & 1446 & 7 & 1342 \\
\hline 76 & 5704 & 1772 & 41 & 1507 & 68 & 1506 & 38 & 1555 & 12 & 1296 \\
\hline 77 & 5733 & 1784 & 69 & 1648 & 21 & 1580 & 29 & 1503 & 22 & 1313 \\
\hline 78 & 5763 & 1858 & 36 & 1769 & 84 & 1631 & 28 & 1546 & 34 & 1414 \\
\hline 79 & 5792 & 1913 & 192 & 1737 & 96 & 1683 & 49 & 1518 & 33 & 1455 \\
\hline 80 & 5822 & 2019 & 84 & 1728 & 36 & 1737 & 17 & 1704 & 87 & 1361 \\
\hline 81 & 5851 & 2212 & 238 & 1716 & 75 & 1667 & 42 & 1593 & 5 & 1477 \\
\hline 82 & 5881 & 2333 & 262 & 1695 & 32 & 1485 & 83 & 1625 & 106 & 1493 \\
\hline 83 & 5910 & & 498 & 1514 & 41 & 1321 & 28 & 1583 & 24 & 1397 \\
\hline Log & $F_{4700}$ & -14 & & -14 & & & & -14 & & \\
\hline & & & & & & & & & & \\
\hline
\end{tabular}


TABLE 6-Continued

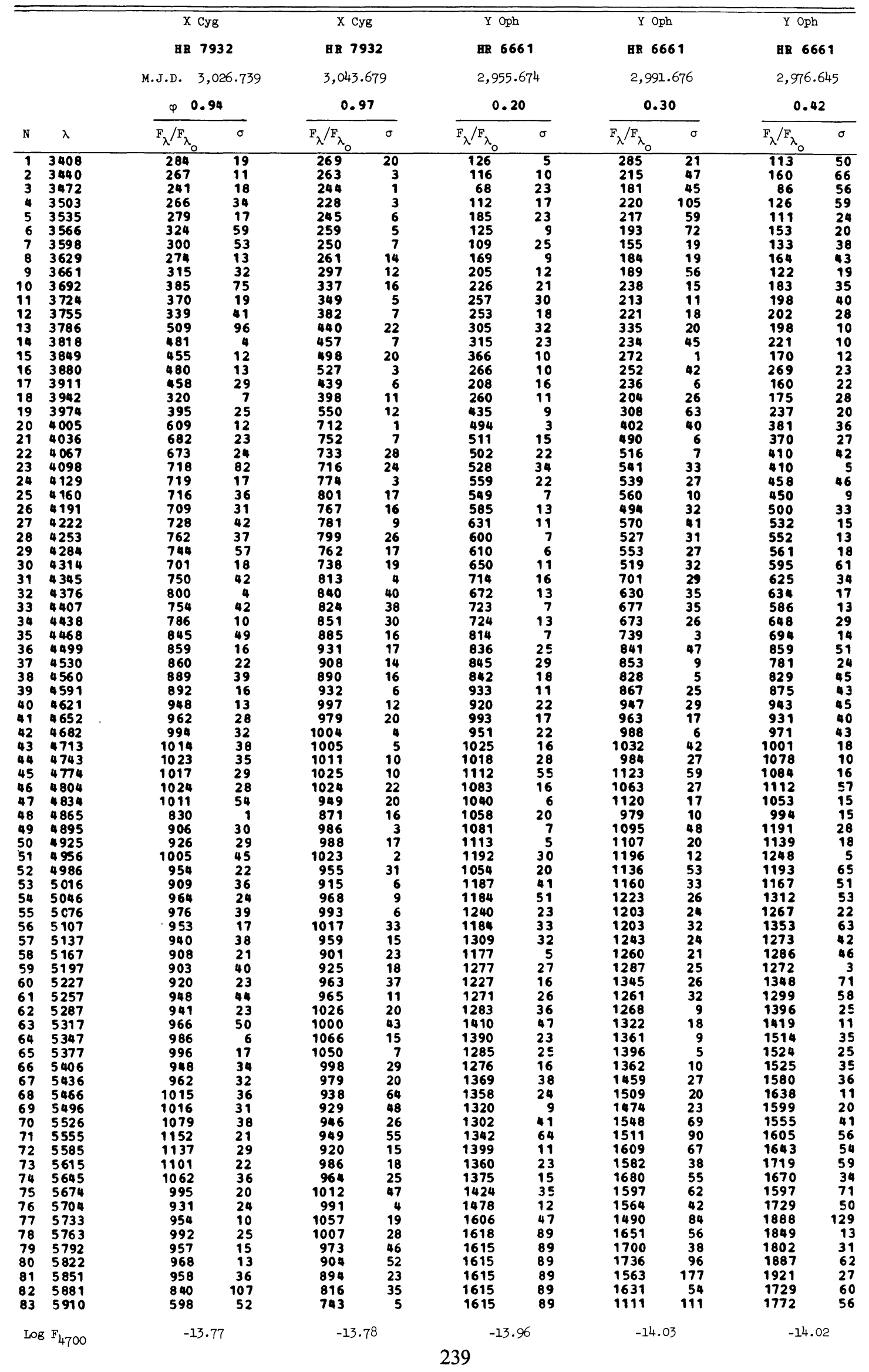


TABLE 6-Continued

\begin{tabular}{|c|c|c|c|c|c|c|c|c|c|}
\hline & & & & & & Y O & & & \\
\hline & & $\mathrm{AR}$ & & BR & & $\mathrm{BR}$ & & BR & \\
\hline & & M.J.D. & 61.673 & 2,9 & & 2,99 & .665 & 3,1 & \\
\hline & & $\varphi 0$ & & & & & & & \\
\hline $\mathrm{N}$ & $\lambda$ & $\mathrm{F}_{\lambda} / \mathrm{F}_{\lambda}$ & $\sigma$ & $\mathrm{F}_{\lambda} / \mathrm{F}_{\lambda_{\mathrm{c}}}$ & $\sigma$ & $\mathrm{F}_{\lambda} / \mathrm{F}_{\lambda_{0}}$ & $\sigma$ & $F_{\lambda} / F_{\lambda_{0}}$ & $\sigma$ \\
\hline $\begin{array}{l}1 \\
2\end{array}$ & $\begin{array}{l}3408 \\
3440\end{array}$ & $\begin{array}{l}83 \\
57\end{array}$ & $\begin{array}{l}21 \\
20\end{array}$ & $\begin{array}{l}62 \\
69\end{array}$ & 76 & 277 & 56 & 122 & 20 \\
\hline $\begin{array}{l}2 \\
3\end{array}$ & $\begin{array}{l}3440 \\
3472\end{array}$ & $\begin{array}{r}57 \\
108\end{array}$ & $\begin{array}{l}20 \\
53\end{array}$ & $\begin{array}{r}69 \\
143\end{array}$ & $\begin{array}{l}13 \\
19\end{array}$ & $\begin{array}{l}117 \\
213\end{array}$ & $\begin{array}{r}51 \\
135\end{array}$ & 168 & 57 \\
\hline 4 & 3503 & 50 & 15 & 80 & 15 & $\begin{array}{l}213 \\
147\end{array}$ & $\begin{array}{l}135 \\
101\end{array}$ & $\begin{array}{l}146 \\
143\end{array}$ & 12 \\
\hline 5 & 3535 & 122 & 36 & 194 & 40 & 188 & 15 & 963 & $\begin{array}{l}14 \\
29\end{array}$ \\
\hline 6 & $\begin{array}{l}3566 \\
3598\end{array}$ & 151 & 10 & 115 & 54 & 117 & 25 & 146 & 6 \\
\hline $\begin{array}{l}7 \\
8\end{array}$ & $\begin{array}{l}3598 \\
3629\end{array}$ & $\begin{array}{l}240 \\
199\end{array}$ & 9 & 163 & 10 & 193 & 31 & 146 & 32 \\
\hline 9 & 3661 & $\begin{array}{l}199 \\
201\end{array}$ & $\begin{array}{l}22 \\
21\end{array}$ & $\begin{array}{l}125 \\
158\end{array}$ & 12 & $\begin{array}{l}112 \\
223\end{array}$ & $\begin{array}{r}13 \\
27\end{array}$ & 183 & 3 \\
\hline 10 & 3692 & 188 & 6 & 199 & 4 & 166 & 36 & $\begin{array}{l}211 \\
232\end{array}$ & 5 \\
\hline 11 & 3724 & 227 & 38 & 175 & 36 & 227 & 94 & 209 & 34 \\
\hline 12 & 3755 & 223 & 29 & 215 & 13 & 229 & 4 & 182 & 19 \\
\hline $\begin{array}{l}13 \\
14\end{array}$ & 3786 & 254 & 14 & 199 & 4 & 306 & 34 & 243 & 22 \\
\hline $\begin{array}{l}14 \\
15\end{array}$ & 3818 & 213 & 16 & 211 & 1 & 225 & 1 & 207 & 6 \\
\hline $\begin{array}{l}15 \\
16\end{array}$ & $\begin{array}{l}3849 \\
3880\end{array}$ & $\begin{array}{l}232 \\
235\end{array}$ & 23 & 190 & 30 & 260 & 15 & 163 & 27 \\
\hline 17 & 3911 & $\begin{array}{l}235 \\
205\end{array}$ & $\begin{array}{l}15 \\
13\end{array}$ & $\begin{array}{l}242 \\
212\end{array}$ & 12 & 167 & 42 & 215 & 9 \\
\hline 18 & 3942 & 216 & 39 & $\begin{array}{l}212 \\
193\end{array}$ & $\begin{array}{l}22 \\
10\end{array}$ & $\begin{array}{l}295 \\
116\end{array}$ & 25 & 230 & 5 \\
\hline 19 & 3974 & 314 & 36 & 267 & 33 & 262 & $\begin{array}{l}25 \\
24\end{array}$ & $\begin{array}{r}183 \\
212\end{array}$ & 6 \\
\hline 20 & 4005 & 386 & 20. & 395 & 6 & 401 & 8 & 360 & 2 \\
\hline 21 & 4036 & 399 & 17 & 460 & 22 & 457 & 3 & 447 & 6 \\
\hline 22 & 4067 & 427 & 47 & 429 & 11 & 392 & 41 & 408 & 6 \\
\hline $\begin{array}{l}23 \\
24\end{array}$ & $\begin{array}{l}4098 \\
4129\end{array}$ & $\begin{array}{l}473 \\
476\end{array}$ & 32 & 448 & 10 & 487 & 0 & 450 & 8 \\
\hline 24 & & $\begin{array}{l}476 \\
466\end{array}$ & 11 & 473 & 20 & 435 & 3 & 469 & 17 \\
\hline $\begin{array}{l}25 \\
26\end{array}$ & $\begin{array}{l}4160 \\
4191\end{array}$ & $\begin{array}{l}466 \\
476\end{array}$ & 23 & 488 & 4 & 529 & 17 & 441 & 13 \\
\hline $\begin{array}{l}26 \\
27\end{array}$ & $\begin{array}{l}4191 \\
4222\end{array}$ & $\begin{array}{l}476 \\
502\end{array}$ & 26 & 466 & 5 & 464 & 16 & 421 & 30 \\
\hline $\begin{array}{l}27 \\
28\end{array}$ & $\begin{array}{l}4222 \\
4253\end{array}$ & $\begin{array}{l}502 \\
487\end{array}$ & 11 & 517 & 12 & 601 & 50 & 485 & 0 \\
\hline $\begin{array}{l}28 \\
29\end{array}$ & $\begin{array}{l}4253 \\
4284\end{array}$ & $\begin{array}{l}487 \\
538\end{array}$ & 7 & 598 & 5 & 531 & 28 & 536 & 17 \\
\hline $\begin{array}{l}29 \\
30\end{array}$ & $\begin{array}{l}4284 \\
4394\end{array}$ & $\begin{array}{l}538 \\
513\end{array}$ & 13 & 542 & 11 & 546 & 2 & 567 & 26 \\
\hline 30 & $\begin{array}{l}4314 \\
4345\end{array}$ & $\begin{array}{l}513 \\
543\end{array}$ & 33 & 590 & 21 & 588 & 70 & 537 & 22 \\
\hline 31 & $\begin{array}{l}4345 \\
4376\end{array}$ & $\begin{array}{l}543 \\
594\end{array}$ & 38 & 598 & 21 & 680 & 8 & 632 & 9 \\
\hline 32 & 4376 & 594 & 37 & 619 & 17 & 633 & 3 & 683 & 28 \\
\hline 33 & 4407 & 613 & 12 & 666 & 67 & 657 & 19 & 686 & 25 \\
\hline 34 & 4438 & 641 & 10 & 674 & 25 & 635 & 5 & 694 & 33 \\
\hline 35 & 4468 & 749 & 41 & 734 & 2 & 738 & 26 & 730 & 36 \\
\hline 36 & 4499 & 779 & 12 & 783 & 7 & 777 & 14 & 862 & 1 \\
\hline 37 & 4530 & 812 & 16 & 753 & 17 & 787 & 4 & 814 & 7 \\
\hline 38 & 4560 & 825 & 19 & 810 & 29 & 828 & 39 & 826 & 17 \\
\hline 39 & 4591 & 881 & 32 & 845 & 17 & 897 & 14 & 869 & 1 \\
\hline 40 & 4621 & 910 & 40 & 914 & 15 & 917 & 3 & 999 & 14 \\
\hline 41 & 4652 & 958 & 24 & 943 & 1 & 958 & 23 & 965 & 15 \\
\hline 42 & 4682 & 966 & 20 & 976 & $i$ & 971 & 38 & 948 & 13 \\
\hline 43 & 4713 & 1025 & 13 & 1012 & 21 & 1060 & 29 & 1024 & 19 \\
\hline 44 & 4743 & 1042 & 22 & 1057 & 16 & 1010 & 4 & 1042 & 28 \\
\hline 45 & 4774 & 1063 & 35 & 1125 & 15 & 1154 & 1 & 1129 & 29 \\
\hline 46 & 4804 & 1060 & 22 & 1093 & 75 & 1112 & 32 & 1160 & 40 \\
\hline 47 & 4834 & 1004 & 62 & 1188 & 35 & 1112 & 10 & 1131 & 8 \\
\hline 48 & 4865 & 1034 & 25 & 1099 & 15 & 1012 & 14 & 1043 & 61 \\
\hline 49 & 4895 & 1060 & 23 & 1139 & 2 & 1115 & 3 & 1081 & 15 \\
\hline 50 & 4925 & $\begin{array}{l}1088 \\
\end{array}$ & 30 & 1167 & 17 & 1125 & 12 & 1091 & 45 \\
\hline 51 & 4956 & 1155 & 30 & 1262 & 7 & 1233 & 31 & 1149 & 9 \\
\hline 52 & 4986 & 1151 & 24 & 1182 & 20 & 1123 & 17 & 1114 & 64 \\
\hline 53 & 5016 & 1159 & 48 & 1183 & 10 & 1148 & 1 & 998 & 19 \\
\hline 54 & 5046 & 1200 & 15 & 1282 & 8 & 1184 & 20 & 1066 & 53 \\
\hline 55 & 5076 & 1230 & 64 & 1331 & 45 & 1276 & 8 & 1208 & 49 \\
\hline 56 & 5107 & 1218 & 17 & 1341 & 56 & 1240 & 12 & 1179 & 73 \\
\hline 57 & 5137 & 1247 & 83 & 1364 & 19 & 1224 & 4 & 1217 & 36 \\
\hline 58 & 5167 & 1327 & 99 & 1363 & 18 & 1241 & 15 & 1144 & 3 \\
\hline 59 & 5197 & 1327 & 67 & 1362 & 1 & 1294 & 35 & 1144 & 38 \\
\hline 60 & 5227 & 1295 & 72 & 1380 & 4 & 1332 & 39 & 1159 & 43 \\
\hline 61 & 5257 & 1376 & 90 & 1385 & 13 & 1330 & 3 & 1183 & 24 \\
\hline 62 & 5287 & 1339 & 18 & 1421 & 27 & 1359 & 24 & 1150 & 55 \\
\hline 63 & 5317 & 1417 & 24 & 1474 & 47 & 1428 & 29 & 1230 & 43 \\
\hline 64 & 5347 & 1416 & 27 & 1493 & 26 & 1426 & 10 & 1217 & 11 \\
\hline 65 & 5377 & 1472 & 93 & 1506 & 41 & 1395 & 18 & 1273 & 36 \\
\hline 66 & 5406 & 1434 & 74 & 1490 & 41 & 1370 & 1 & 1157 & 27 \\
\hline 67 & 5436 & 1542 & 58 & 1461 & 26 & 1356 & 12 & 1281 & 66 \\
\hline 68 & 5466 & 1525 & 58 & 1544 & 46 & 1487 & 30 & 1271 & 43 \\
\hline 69 & 5496 & $\begin{array}{l}1598 \\
1534\end{array}$ & 95 & 1560 & 30 & 1465 & 68 & 1139 & 40 \\
\hline 70 & 5526 & 1534 & 69 & 1637 & 70 & 1515 & 29 & 1286 & 47 \\
\hline 71 & 5555 & 1582 & 101 & 1729 & 17 & 1521 & 10 & 1296 & 26 \\
\hline 72 & 5585 & 1569 & 93 & 1744 & 68 & 1581 & 36 & 1245 & 24 \\
\hline 73 & 5615 & 1539 & 92 & 1808 & 63 & 1529 & 19 & 1331 & 75 \\
\hline 74 & 5645 & 1562 & 104 & 1853 & 37 & 1639 & 148 & 1349 & 32 \\
\hline 75 & 5674 & 1573 & 33 & 1674 & 12 & 1435 & 78 & 1393 & 15 \\
\hline 76 & 5704 & 1611 & 69 & 1904 & 32 & 1583 & 19 & 1347 & 7 \\
\hline 77 & 5733 & 1708 & 62 & 1920 & 49 & 1481 & 8 & 1498 & 10 \\
\hline 78 & 5763 & 1714 & 119 & 2004 & 52 & 1760 & 57 & 1425 & 20 \\
\hline 79 & 5792 & 1657 & 135 & 2063 & 95 & 1634 & 13 & 1338 & 47 \\
\hline 80 & 5822 & 1680 & 142 & 2219 & 33 & 1826 & 92 & 1551 & 75 \\
\hline 81 & 5851 & 1756 & 168 & 2091 & 34 & 1651 & 83 & 1402 & 6 \\
\hline 82 & 5881 & 1728 & 176 & 2031 & 112 & 1658 & 158 & 1270 & 34 \\
\hline 83 & 5910 & 1391 & 194 & 1671 & 78 & 1358 & 83 & 1032 & 106 \\
\hline Log & $F_{4700}$ & -13. & & -14 & & -14 & & & \\
\hline
\end{tabular}




\section{REFERENCES}

Blanco, V. M., Demers, S., Douglass, G. G., and FitzGerald, M. P. 1968, Pub. US Naval Obs., 2d Ser., Vol. 21.

Cox, A. N., King, D. S., and Tabor, J. E. 1973, Ap. J., 184, 201.

Feinstein, A. 1959, Zs. Ap., 47, 224.

. 1967, Ap.J., 149, 107.

Feltz, K. A., Jr., and McNamara, D. H. 1976, Pub. A.S.P., 88 , 699.

Fernie, J. D. 1967, A.J., 72, 422.

Fernie, J. D., and Hube, J. O. 1968, A.J., 73, 492.

. 1971, Ap. J., 168, 437.

FitzGerald, M. P. 1970, Astr. Ap., 4, 234.

Hoffleit, D. 1964, Catalogue of Bright Stars (3d rev. ed.; New Haven: Yale University Observatory).

Johnson, H. R. 1974, NCAR Tech. Note, No. STR-95, p. 82.

Keenan, P. C. 1963, in Basic Astronomical Data, ed. K. Aa. Strand (Chicago: University of Chicago Press), p. 92.

Kraft, R. P. 1961, Ap.J., 134, 616.

Kraft, R. P., and Hiltner, W. A. 1961, Ap. J., 134, 850.

Kraft, R. P., Preston, G. W., and Wolff, S. C. 1964, Ap. J., 140, 235.

Kron, G. E. 1978, private communication.

Kukarkin, B. V., et al. 1969, General Catalogue of Variable Stars (3d ed.; Moscow).

Makarenko, E. N. 1971, Soviet Astr.-AJ, 14, 970.
Mitchell, R. I., Iriarte, B., Steinmetz, D., and Johnson, H. L. 1964, Bol. Obs. Tonantzintla y Tacubaya, 3, No. 24, 153.

Neff, J. S., and Clements, G. L. 1972, University of Iowa Research Rept. 72-22.

. 1973, Bull. AAS, 4, 335

Neff, J. S., Ketelsen, D., Schmidt, G. D., and Tatum, J. B. 1976, Icarus, 27, 545.

Nikolov, N. S. 1967a, Soviet Astr.-AJ, 10, 623. 1967b, Soviet Astr.-AJ, 11, 92.

Osmer, P. S. 1972, Ap. J. Suppl., 24, 247.

Parsons, S. B. 1969, Ap. J. Suppl., 18, 127. 1971, M.N.R.A.S., 152, 121 .

Parsons, S. B., and Bouw, G. D. 1971, M.N.R.A.S., 152, 133. Sandage, A., and Tammann, G. A. 1968, Ap.J., 151, 531.

Schild, R. E. 1977, A.J., 82, 337.

Schmidt, E. G. $1972 a$, Ap. J., $172,679$.

. 1972b, Ap. J., 174, 595 .

Schmidt, E. G., Rosendhal, J. D., and Jewsbury, C. P. 1974, Ap. J., 189, 293.

Schmidt-Kaler, Th. 1961, Zs. Ap., 53, 1.

Schneider, M. 1969, Astr. Ap., 2, 195.

Shane, W. W. 1958, $A p$. J., 127, 573.

Underhill, A. B., and Walker, G. A. H. 1966, M.N.R.A.S., 131, 475 .

Wielen, R. 1974, Astr. Ap. Suppl., 15, 1.

Wilson, O. C., and Bappu, M. K. V. 1957, Ap. J., 125, 661.

JoHn S. NefF: Department of Physics and Astronomy, University of Iowa, Iowa City, IA 52242

Robert S. Patterson: Department of Physics, Southwest Missouri State University, Springfield, MO 65802 